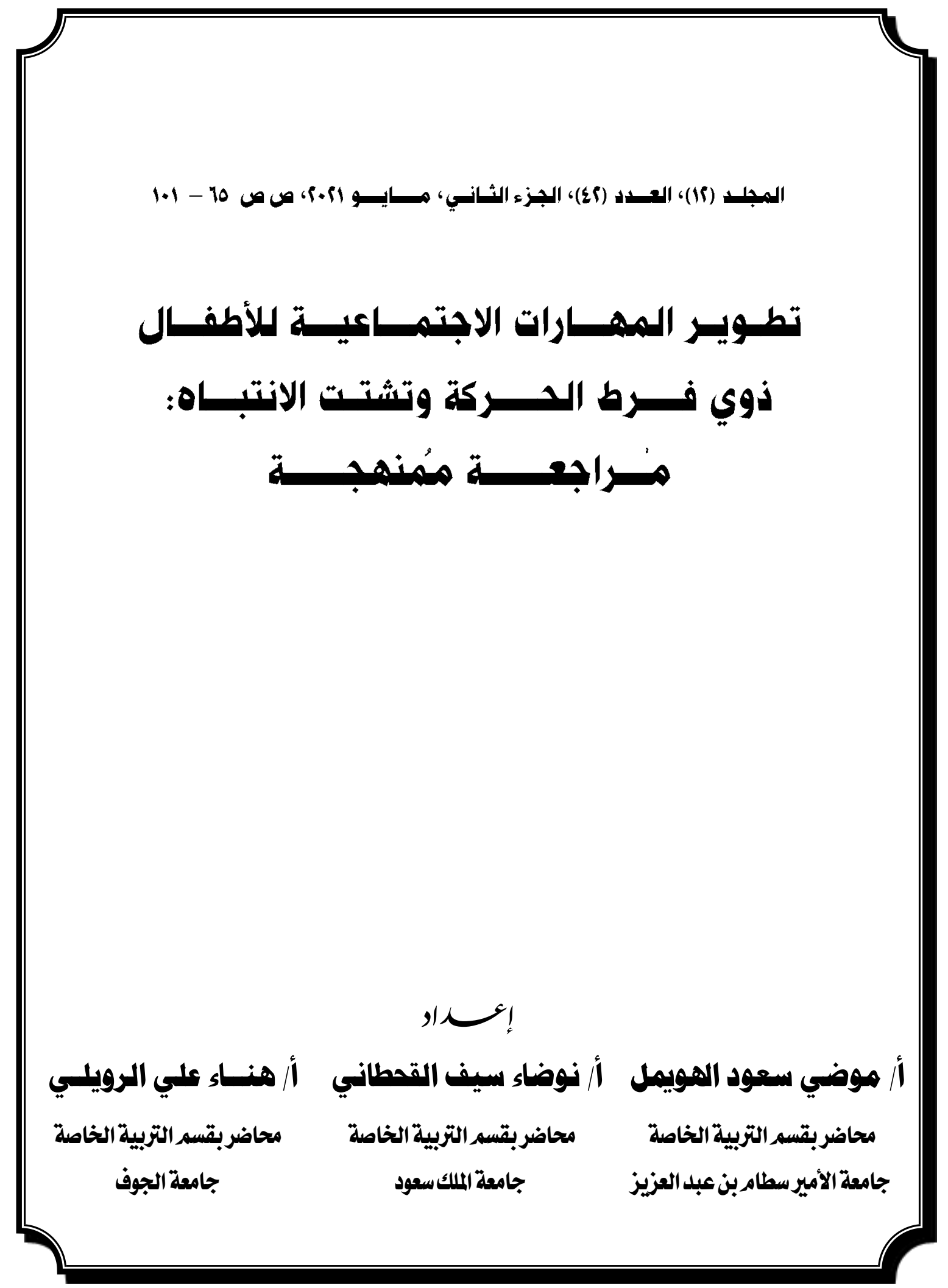




\section{مسراجعسة مسمنهج}

\section{إنـ}

أ/ موضي سعود الهويمل (*) \& أ/ نوضاء سيف القحطاني (*) \& أ/ هناء علي الرويلي(***)

\section{هid}

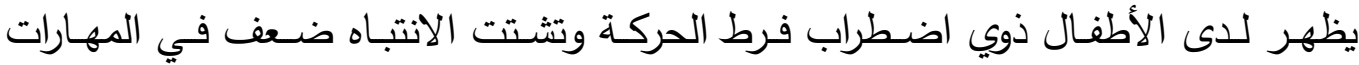

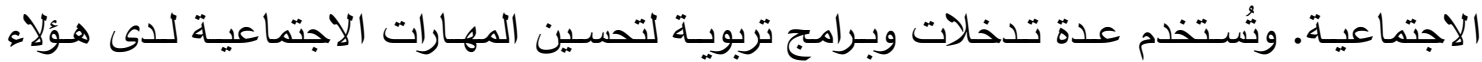

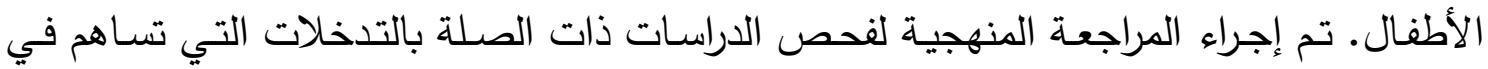
تطوير المهارات الاجتماعية للأطفال ذوي اضطراب فرط الحركة وتثتت الانتباه. اشتملت المراجعة

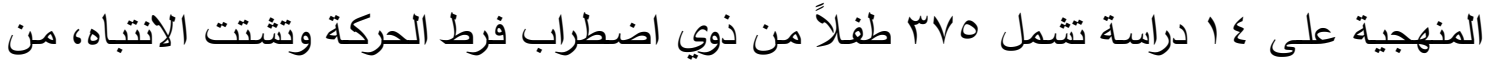
خلال ست قواعد بيانات الكترونية، باستخدام ست مصطلحات في البحث. تم اختيار الدراسات وفقاً

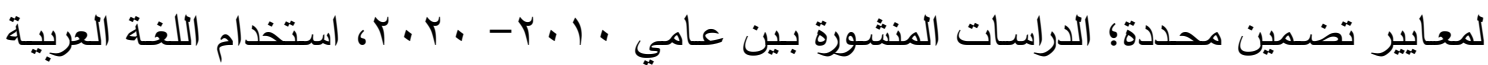

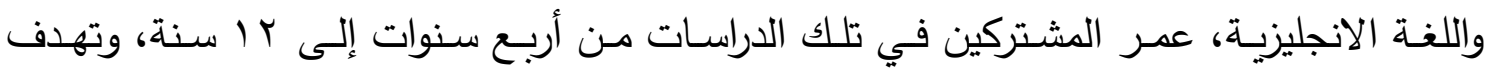

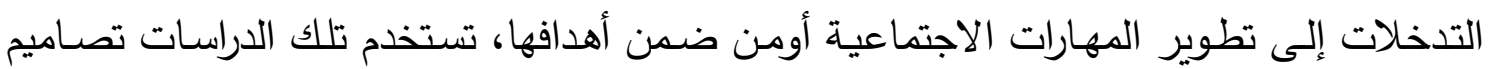

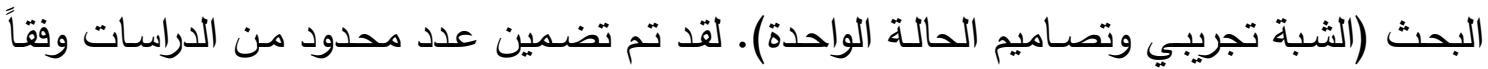
لمعايير القبول والاستبعاد. بالإضافة إلى ذلك، لم تتضمن هذه المراجعة الرسائل والدراسات غير الترائ

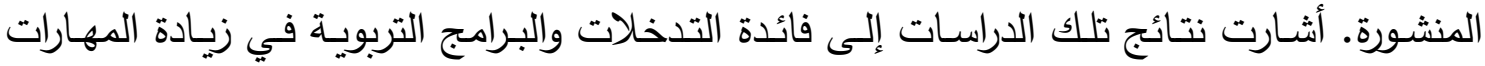
الاجتماعية المقبولة اجتماعياً وانخفاض السلوكيات غير المبولة. ووفقاً لمعايير مجلس الأطفال

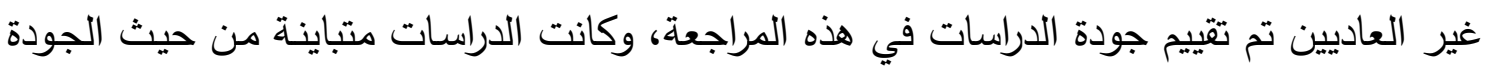

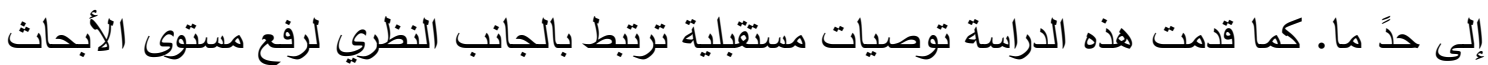

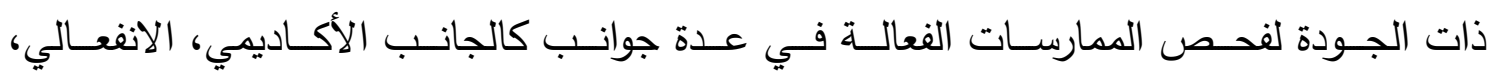
والاجتماعي، وكذلك تطوير الجانب التطبيقي المرتبط بالقائمين على تتفيذ تلك التحخلات. الكلمـات المفتاحيـة: اضطراب فرط الحركة وتثتت الانتباه، الأطفال ذوي فرط الحركة وتثتت الانتباه، التخخلات والبرامج التربوية، المهارات الاجتماعية.

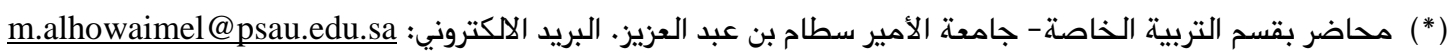

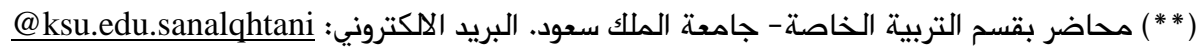

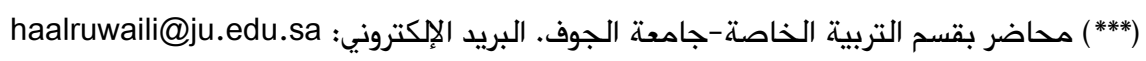




\section{Developing the Social Skills of Attention Deficit Hyperactivity Disorder Children: A Systematic Review $\square$}

\section{By \\ Mody Alhowiml $^{(*)}$ \& Nawdha Alkahtani ${ }^{(* *)}$ \& Hana Alruwaili ${ }^{(* * *)}$ \\ Ahstract}

Children with Attention Deficit Hyperactivity Disorder (ADHD) seem to have insufficient social skills. Several educational interventions and programs use to improve the social skills of these children. The current systemic review examines studies related to interventions that contribute to developing social skills in children with ADHD. The systematic review included 14 studies covering 375 children with ADHD through six electronic databases, using six terms in the search. Studies were selected according to specific inclusion criteria. The studies published between 2010-2020, using of the Arabic and the English language, the age of the participants in those studies ranged from four to twelve years, and the interventions aim to develop social skills, or among their objectives, these studies use research designs (quasi-experimental and single subject designs). A limited number of studies have been included according to inclusion and exclusion criteria. Additionally, this review did not include unpublished articles and studies. The results of these studies indicated the usefulness of educational interventions and programs in increasing socially acceptable social skills and reducing unacceptable behaviors. The quality of the studies in this review was assessed according to the criteria of the Council for Exceptional Children (CEC). The studies were, to some extent, mixed quality. This study provided recommendations for future research and practices to increase research on effective interventions and practices in several aspects, such as the academic, emotional, and social aspect.

Key words: Attention Deficit Hyperactivity Disorder, Children with hyperactivity and attention deficit, Educational interventions and programs, Social skills.

(*) Lecturer at Special Education Department- Prince Sattam Bin Abdulaziz University, Email: m.alhowaimel@psau.edu.sa

(**) Lecturer at Special Education Department- King Saud University, Email: nalqhtani@ksu.edu.sa

(***) Lecturer at Special Education Department- Al-Jouf University, Email: haalruwaili@ju.edu.sa 
يُشَّل اضطراب فرط الحركة وتثتت الانتباه كأحد الاضطرابات السلوكية مُشكلة حقيقية لدى أطفال المدارس؛ ممـا يُسهِمِ في خلق صـوبات لديهم أثناء عملهم على تحقيق الأهداف المطلوبة منهم، كالأهداف الأكاديمية والاجتماعية. إذ يُعرف اضطراب فرط الحركة وتشتت الانتباه بكونه شكل من أشكال السلوك يتسم بالاستمرارية من عدم الاهتمام، فرط النشاط والاندفاعية التي تتعارض مـع الأداء والنمو؛ بحيث يظهر على الطفل ذو اضطراب فرط الحركة وتثتت الانتباه

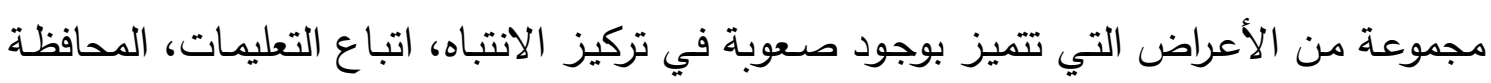
على ممتلكاته، وانتظار الدور (American Psychiatric Association, 2013). كما تجدر الإثارة إلى أن هذا الاضطراب من أكثر الاضطرابات السلوكية شيوعًا والمُصنف ضمن الإعاقات

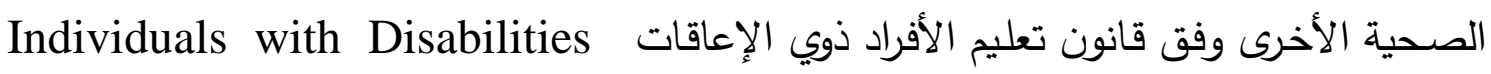
Education Act

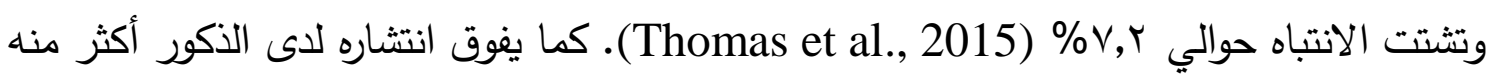
لاى الإناث (Thomaidis et al., 2017). يتسم الأطفال ذوي اضطراب فرط الحركة وتثتت الانتباه بمجموعة من الخصائص التي

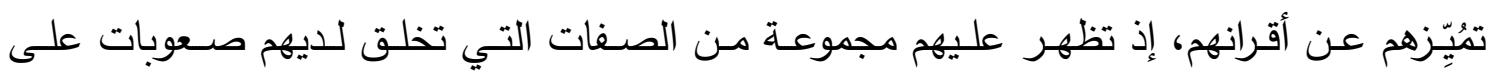

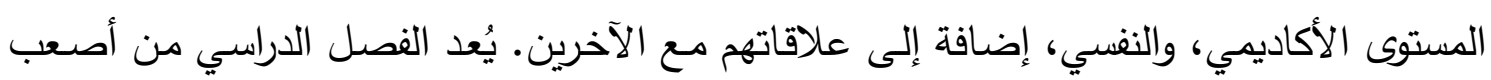

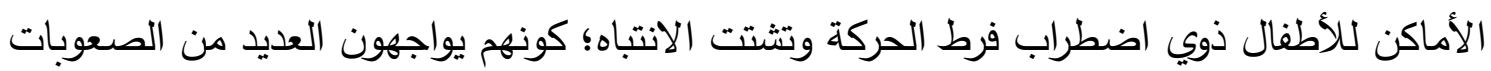

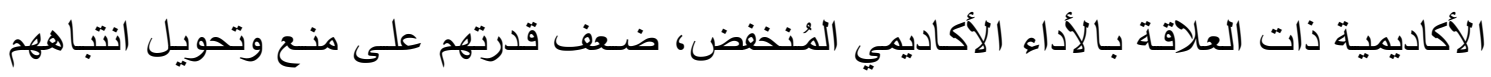
بثكل مُناسب، واحتماليـة تعرضـهم للمشـاكل ذات العلاقـة بالجانب المعرفي، التـي مـن أبرزهـا

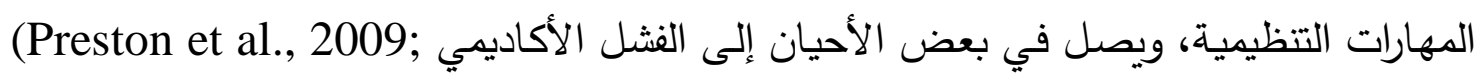
كما يظهر عليهم مشكلات على صعيد Thapar et al., 1999; Thomaidis et al., 2017)

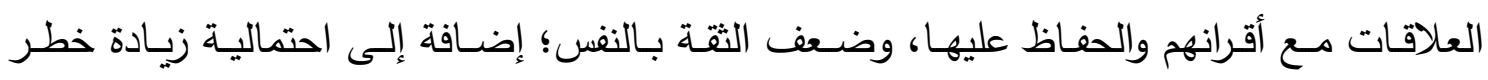
التعرض لصعوبات نفسية واجتماعية في مرحلة البلوغ (Thapar et al., 1999). فالطفل العادي يرتبط سلوكه بما يتناسب مع عادات وتقاليد مجتمعه الذي يتعايش معـاه وقدرته على التواصل الجيد مـع الاخرين، وعلى عكس ذلك الطفل الذي يعاني من اضطرابات 
نمائية كاضطراب فرط الحركة وتثتت الانتباه، يفتقد إلى الكثير من الحياة الاجتماعية الناجحة بسبب عدم إمكانيته للاستجابة للمثيرات بشكل طبيعي (William et al., 2000). وأشار المعيقل

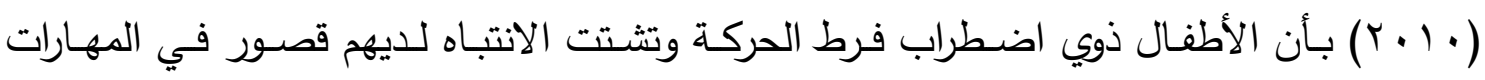
الاجتماعية مما تؤثر سلبيًا على علاقاتهم الاجتماعية وتفاعلهم مع أقرانهم والأخرين.

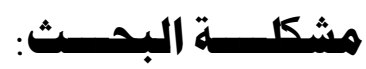

أكدت البحوث والدراسات أن من المشكلات الاجتماعية لدى الاطفال ذوي اضطراب فرط الحركة وتشتت الانتباه الانسحاب الاجتماعي، عدم القدرة على التعبير عن مشاعرهم، عدم ضبط (Kats-Gold \& Priel, 2009; انفعالاتهم وصعوبة في تكوين علاقات اجتماعية جيدة (William et al., 2000) لذلك، فالمهارات الاجتماعية مهمة للطفل حيث تمكنه من التكيف والتعــايش مـع المجتــع وتسـاعده في التعامـل مـع المواقف الصـعبة والجديـدة، إذ أن المهـارات الاجتماعية من العناصر الأساسية للحفاظ على تفاعل الطفل مع الاخرين بطريقة إيجابية والقدرة على إقامة علاقات ناجحة للطفل مع من حوله (Kearney \& Healy, 2011). فنجد الأطفال الذين يعـانون مـن اضـطراب فرط الحركـة وتشتت الانتبـاه غالبًا مـا يـتم رفضهم من قبل أقرانهم بسبب قيامهم ببعض التصرفات أو السلوكيات غير المقبولة اجتماعياً. على سبيل المثال قيامه بسلوكيات عدوانية تجاه الاخرين، عدم القدرة على تكوين علاقات وصداقة مع الاخرين وسوء تصرف كقيامه بسلوك لا يناسب الموقف (Grygiel, 2018). وذكرا Kats-Gold)

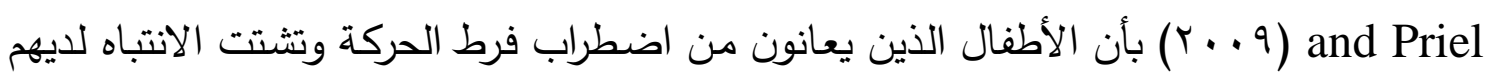
ضـف في الفهم الانفعالي، حيث يؤثر هذا الضعف في الفهح الانفعالي على الأداء الاجتماعي

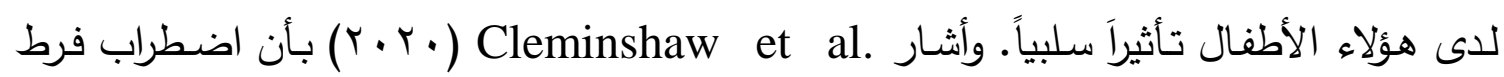
الحركة وتشتت الانتباه يرتبط ارتباطاً وثيقاً بقصور الأداء الاجتماعي لدى المراهقين. ومع ذلك فإن

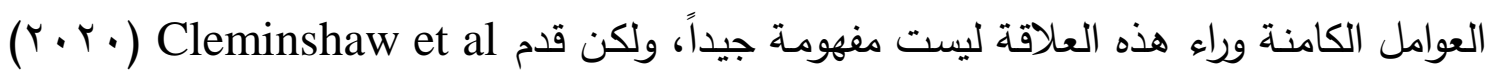
دليلاً على أن عدم انتظـام العاطفـة يمكن أن يفسر العلاقـة بين اضـراب فرط الحركة وتشتت الانتباه والعجز الاجتماعي لدى هؤلاء المراهقين. 


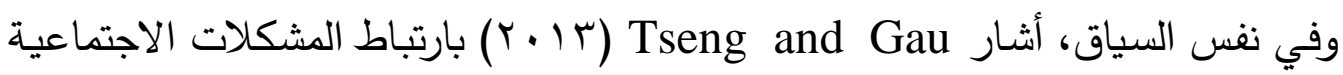
وصعوبة تكوين علاقة جيده مع الأقران لدى الافراد الذين يعانون من اضطراب فرط الحركة وتشتت

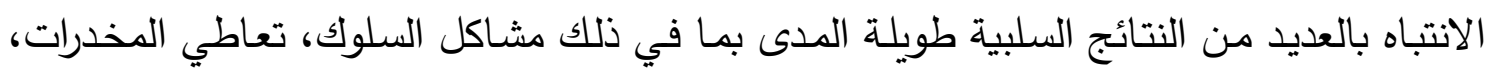

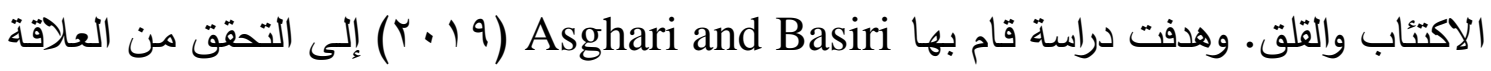
بين اضطراب فرط الحركة وتثتت الانتباه مـع إدمان الانترنت والاكتئاب والقلق والتوتر والرهاب الاجتماعي، إذ اسفرت النتائج بأن هناك علاقات إيجابية بينهم.

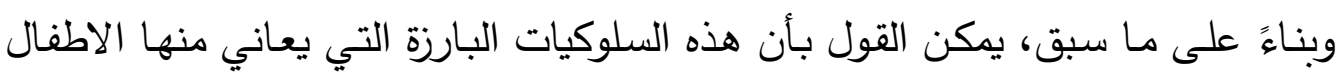

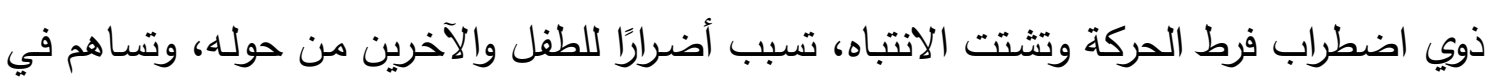

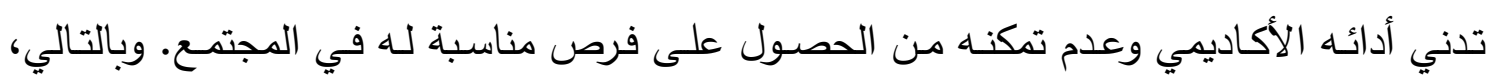

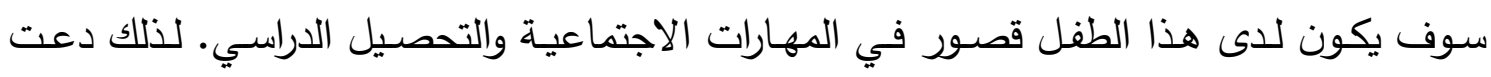

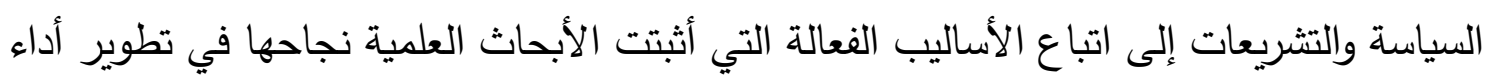

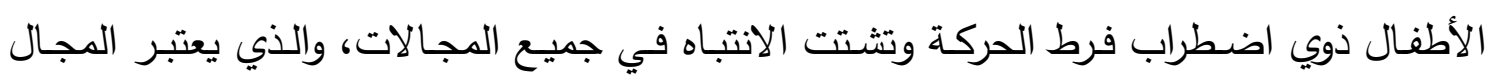

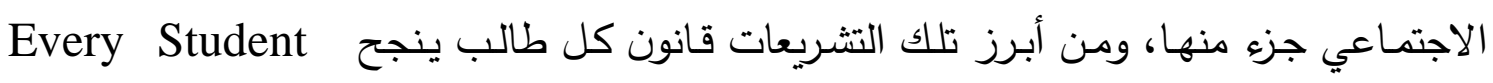
Succeeds Act (ESSA)

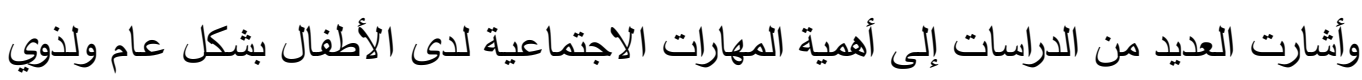

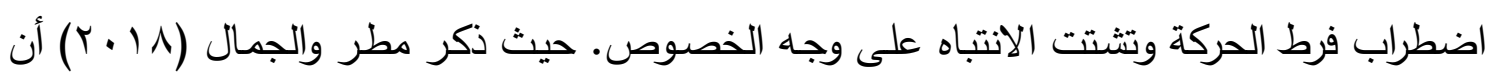
استخدام البرامج والاستراتيجيات في خفض اضطراب قصور الانتباه وما يصـاحبه من نشاط زائد

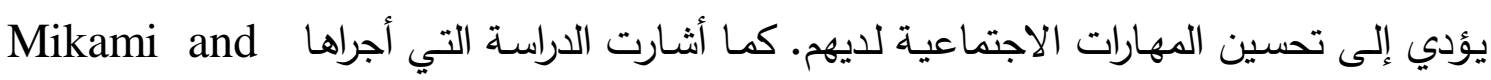

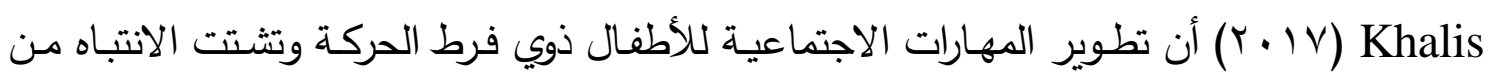
خلال استخدام التدخلات والممارسات المبنية على البيانات تعطي فاعلية واعدة في خفض المشاكل

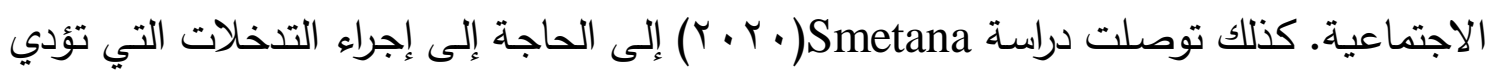
إلى تحسين الكفاءة الاجتماعية لاى الأطفال ذوي فرط الحركة وتثتت الانتباه، وذلك بعد تطبيق عدد إلى

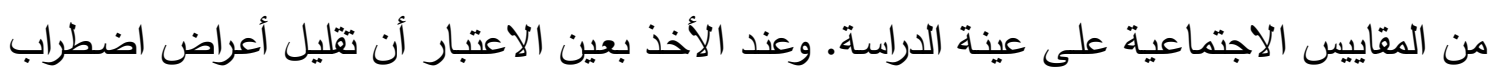

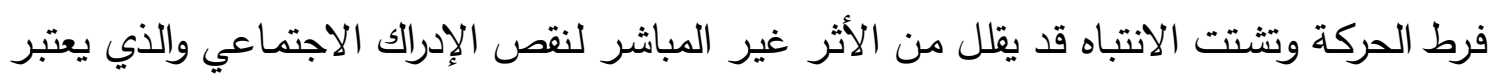

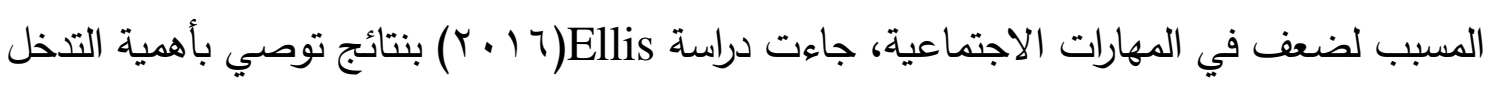


وتطبيق الإجراءات التي تساهم في تطوير المهارات الاجتماعية. تأتي هذه المراجعة المنهجية الحالية

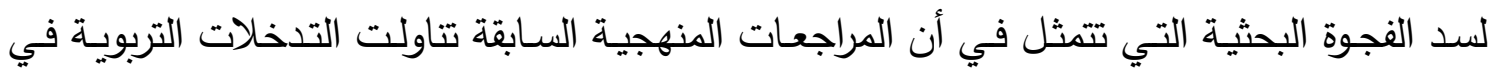

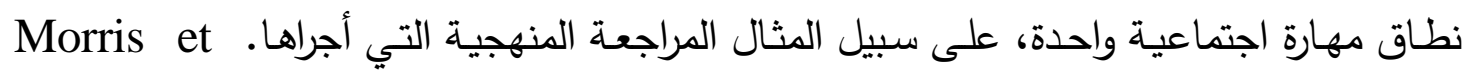

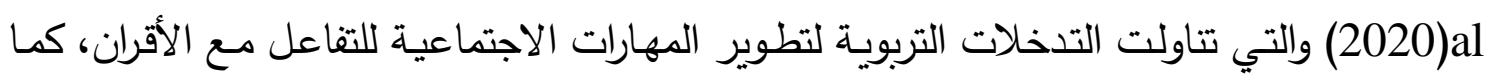

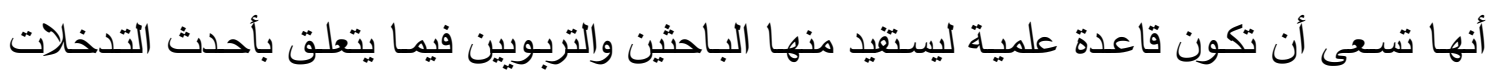
التربوية التي تسهم في تطور المهارات الاجتماعية.

يأتي الهذف الأساسي لهذه المراجعة المنهجية في فحص الدراسات التي تتناول التدخلات

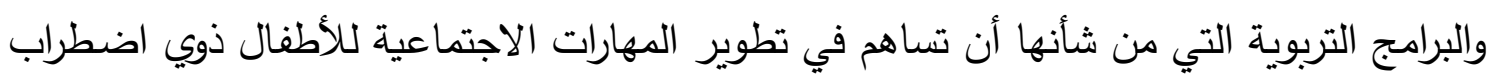
فرط الحركة وتشتت الانتباه.

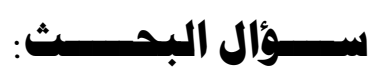

لتحقيق هذا الهدف تم وضـع السؤال التالي: ماهي التدخلات التي ساهمت في تطوير المهارات الاجتماعية للأطفال ذوي فرط الحركة وتشتت الانتباه؟.

من خـلال البحث الحالي اتبعنـا المراجعة المُمنهجة كمنهجية للبحث؛ للوصول إلى أبرز

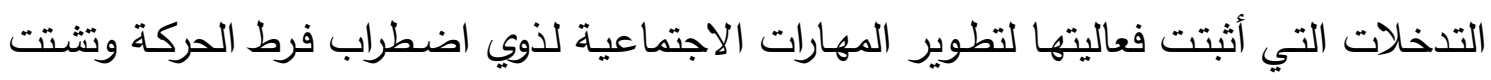
الانتباه. والتي اشتملت على عدد من الخطوات المتسلسلة. بدءًا بصياغة مُشكلة البحث في سؤال بحثي واضح، مع تحديد معايير القبول والاستبعاد؛ تلا ذلك تطوير وبناء استراتيجية البحث المُتبعة بما فيها سلاسل البحث عن الدراسات؛ بعد الانتهاء من عملية البحث عن الدراسات، طُبقت معايير القبول والاستبعاد على كل دراسة وفق نموذج للتحقق من انطباق كل معيار على الدراسة (جدول رقم ()؛ عَقب ذلك جمع واستخراج البيانات من الدراسات التي انطبقت عليها معايير القبول الئحددة في برتوكول البحث، وتقييم الجودة لكل دراسة؛ وفي الخطوة التي بعدها تم تحليل وتوليف النتائج

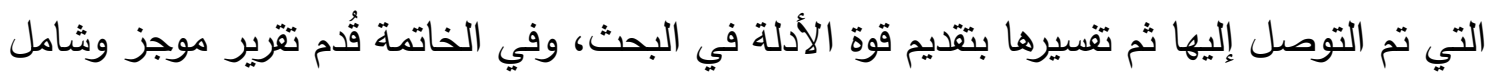
لما توصل إليه البحث الحالي (Boland et al., 2017; Bronson\& Davis, 2012). 


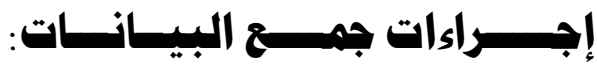

\section{ير القبــول والاستبعــاد:}

تم اختيار الدراسات في هذه المراجعة المُمنهجة وفقاً لمعايير تضمين محددة. أولاً: اختيار

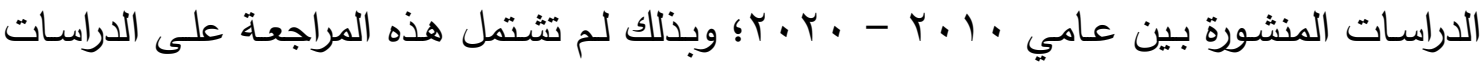
التي نُشرت قبل عام • ( • ب، بهدف التركيز على التدخلات الحديثة. ثانياً: استخدام اللغة العربية والانجليزية بشكل مُحدد؛ واستثناء بقية اللغات؛ للاستفادة من التراث الأجنبي والمحاولة في تأسيس مرجع يُثري المكتبات العربية. ثالثاً: تم تحديد الدراسات المتعلقة بالأطفال من عمر أربع سنوات إلى با سـنة؛ لندرة الدراسـات وبالإضـافة لتركيز الدراسـات حول هذه المرحلـة. رابعًا: اشـمال عينـة الدراسة أو جزء منها على الأطفال ذوي اضطراب فرط الحركة وتشتت الانتباه؛ وبذلك لم تتضمن المراجعة الدراسـات التي لم تشتمل في عينتها على مُشـاركين مـن الأطفال ذوي اضطراب فرط الحركة وتشـتت الانتبـاه. خامسًا: يهدف التدخل أو البرنـامج المُستخدم في الدراسـة إلى تطوير المهارات الاجتماعية أو يقع هدف تطوير المهارات الاجتماعية ضمن أحد أهدافها؛ وفقًا لذلك تم استبعاد أي دراسـة يركز التدخل أو البرنامج فيها على تطوير المهارات الأخرى غير الاجتماعية؛ وأخيراً: تم اختيار تصاميم البحث (الثبة تجريبي وتصاميم الحالة الواحدة) بسبب أن هذه التصاميم تقيس الأثر بشكل فعلي وبالإضـافة إلى ذلك، تُستخدم هذه التصاميم بشكل كبير من قبل الباحثين في التربية الخاصة؛ وبذلك أستثنيت الدراسات التي تتناول المناهج البحثية الأخرى.

تم إجراء هذه المراجعة المُمنهجة لفحص التدخلات الفعالة في تطوير المهارات الاجتماعية للأطفال ذوي فرط الحركة وتشتت الانتباه، وذلك من خلال بحث إلكتروني شامل لستة قواعد بيانات Education Resources Information ، Web of Science (ISI)،إكترونية: المنظومة SAra and GEorge (SAGE) and Elton B. Stephens ‘Center (ERIC) COmpany ProQuest, (EBSCO) للدراسات لأنها تحتوي على مجموعة متتوعة من الدراسات المنشورة حول التربية والتربية الخاصـة، وباستخدام ست مصطلحات رئيسية في البحث لتحديد الدراسـات ذات الصـلة بالدراسـة: تدخلات 
أ / موضي الهويمل \& أ/ نوضاء القحطاني \& أ/ هناء الرويلي تطوير المثارات الاجتماعية للأطفال ذوي فرط الحركة وتشتت الانتباه

المهارات الاجتماعية وذوي فرط الحركة وتشتت الانتباه، المهارات الاجتماعية وذوي فرط الحركة وتشتت الانتباه، التتخلات والمهارات الاجتماعية، العلاقات الاجتماعية وذوي فرط الحركة وتشتت الانتباه، فرط الحركة وتشتت الانتباه، فرط الحركة. وباللغة الإنجليزية:

Social skills interventions and Attention Deficit Hyperactivity Disorder, Social skills and children with Attention Deficit Hyperactivity Disorder, Social interventions and skills, Social relationships and children with Attention Deficit Hyperactivity Disorder, Attention Deficit Hyperactivity Disorder Hyperactivity, Hyperactivity.

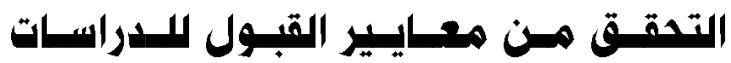

بعد إدخال الكلمات المفتاحية المُستخدمة في هذه المراجعة، كانت نتائج البحث الإجمالية

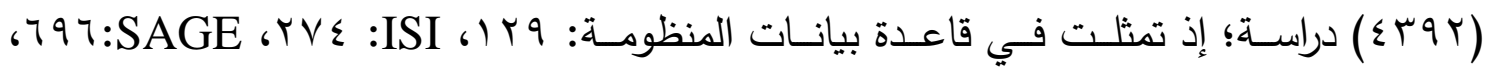
ProQuest هذه المراجعـة مبدئيًا مـن خـلال فحص عنـاوين وملخصـات الدراسـات، كمـا تم الرجوع إلى كامل الدراسة لبعض الدراسات التي يتسم فيها الملخص بعدم الثمولية للمعلومات؛ ففي بعض الدراسات لم يتضح جميع الأهداف الفرعية التي اشتملت عليها الدراسة، مما يستدعي الرجوع للدراسـة نفسها وقراءة جانب الأهداف، حيث أصبحت عدد الدراسات التي تم الحصول عليها (Tr). وبعد التحقق من مدى انطباق معايير القبول لكل دراسـة وفق نمـوذج تم بنـاءه لهذا الغرض كما في الجدول رقم ((في الملاحق)، تم استبعاد عدد من الدراسات؛ كون المعايير لم تتطبق إما بسبب المنهجية، تركيـز الهـدف على جوانـب أخـرى غيـر المجـال الاجتمـاعي، تتـاول مرحلـة عمريـة أكبـر مـن مرحلـة الطفولـة، أو بسـبب التكـرار ؛ حيث يصـبح عـد الدراسـات التـي اتفقـت عليهـا الباحثـات بنسبة ه9\% وتـوفر المعـايير المُدرجـة فيها (ع () دراسـة. ويوضـح الشكل ا العمليـة الانسـيابية لفحص الدراسات. 


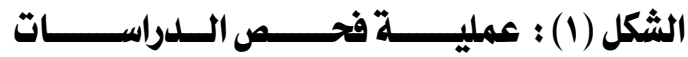
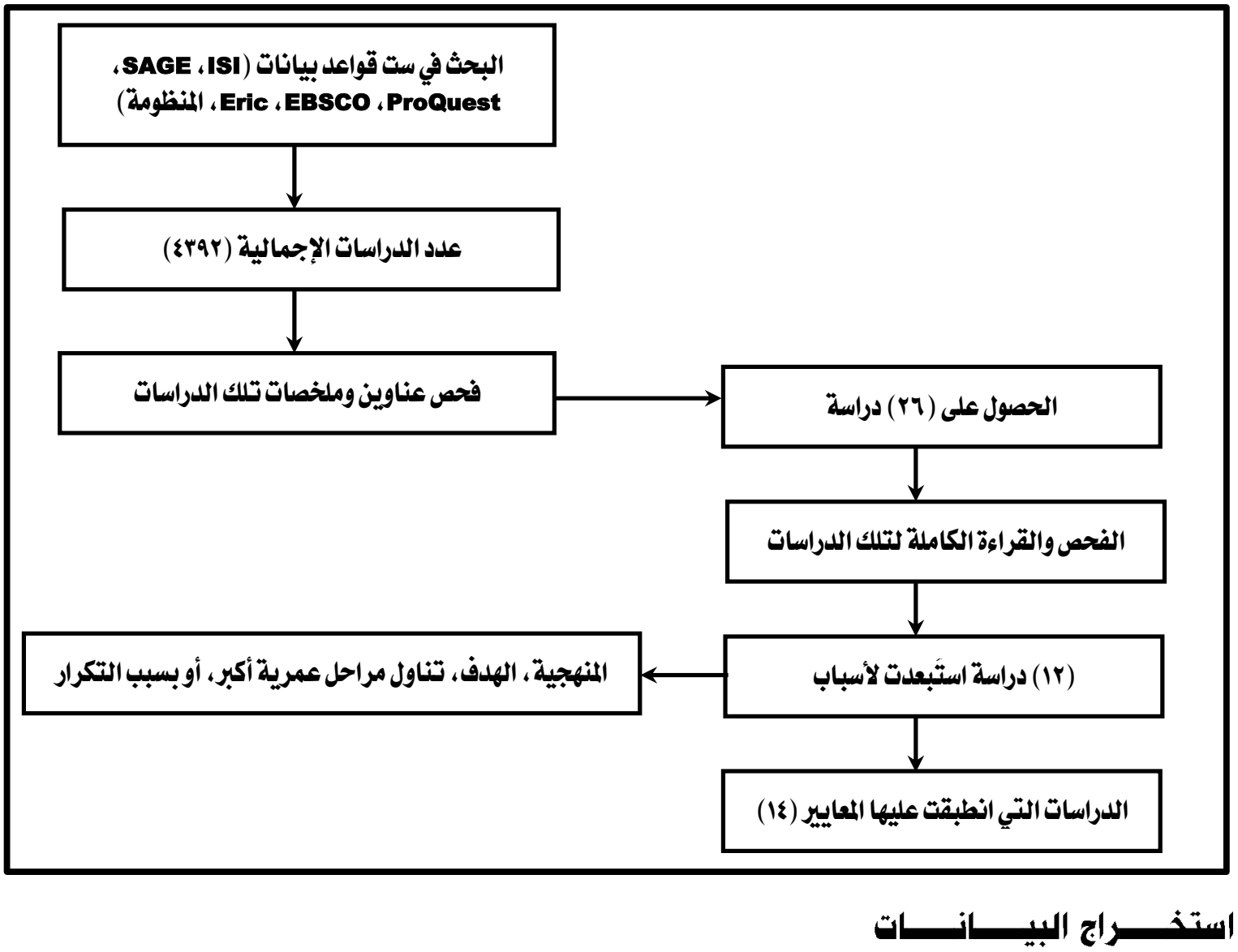

أُتُبع في هذه المرحلـة مـن المراجعـة المتمثلـة في استخراج البيانـات مـن الدراسـات التي

أنطبقت عليها معايير القبول عدد من العمليات ذات العلاقة. أولاً: تم اعتماد وتطوير نموذج ترميز البيانات من خلال الاطلاع على المراجع والأمثلة على النماذج التي عُملت في هذا الثأن، حيث اشتمل الجدول الأول للنمـوذج على بيانـات مُتمثلة في عنـوان الدراسـة، المؤلفـ، السنة، المجلـة، الدولة، المُراجع، المُدقق، الفروض أو الأسئلة، أهداف الدراسـة، ومعايير التضمين كما هو موضـح في جدول رقم r (في الملاحق)؛ أمـا الجداول الأخـرى فتضــت معلومـات حـول المشـاركين، participants, interventions, comparisons, outcomes, and التخخل، المقارنة، والنتائج PRISMA, 2009) study design (PICOS) الإحصـائية وأدوات الصدق والثبات ونتائجها، كما في جدول رقم بو ؛(في الملاحق). ثانيًا: تم تطبيق ذلك النمـوذج على جميع الدراسـات، بحيث تناولت الباحثات كل دراسـة على حدة ومـا تتضمنه من معلومات، لاستخراجها وتضمينها في نموذج ترميز البيانات. كانت مناقثات الباحثات 
حول استخراج وترميز بيانات الدراسات عن بعد باستخدام برنامج التواصل (الواتس اب) والمراسلة عن طريق البريد الاكتروني.

\section{عملية المراجعة وتقييم جودة الدراسات}

ارتكزت عملية تقييم جودة الدراسات المستخرجة على معايير مجلس الأطفال غير العاديين Council for Exceptional Children (CEC) التربية الخاصة، حيث تحتوي على ثمانية معايير رئيسية وكل معيار رئيسي يتضمن معايير أخرى فرعية يتم من خلالها الحكم على جودة تلك الدراسـات ذات التصساميم الثبه تجريبية ودراسـات تصميم الحالة الواحدة. في هذه المراجعة اتفقت الباحثات على تصنيف الدراسات إلى دراسات عالية الجودة، متوسطة الجودة، ومنخفضـة الجودة. فالدراسات عالية الجودة تلك الدراسات التي حققت فئس

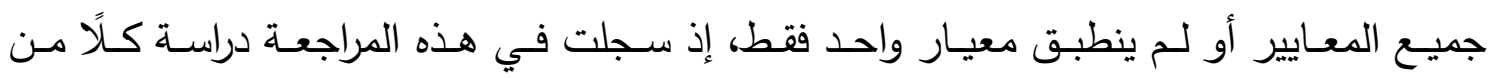
;Campeño-Martínez et al. (2017) Daffner et al. (2020) ; Pfiffner et al.

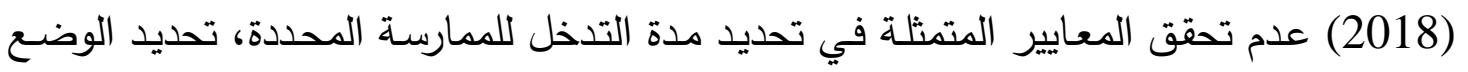
الاجتماعي للمشاركين، أو معايير تحديد المشاركين كما هو محدد في قائمة معايير CEC. أمسا

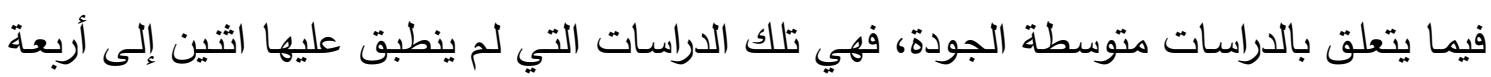

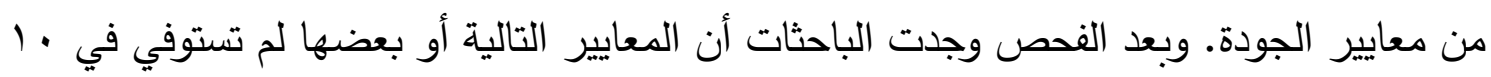
دراسات وهي: عدم استخدام إحصاء لتحديد حجم التأثير المناسب، نقص في المعلومات الديمغرافية للمشاركين، عدم ذكر الصدق الداخلي، معيار الإخلاص في التنفيذ لم ينطبق بالكامل، وكانت

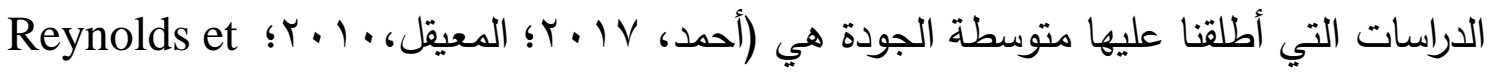
al,2014; Wilkes-Gillan et al., 2014 a; Wilkes-Gillan et al.,2016 b; Jijina\&Sinha,2016; Corkum et al.,2010; Jurjadeh et al., 2018; Pana et al.,2016; Feil et al.,2016; ينطبق عليها خمسـة معـايير فـأكثر مـن معـايير الجودة وكانت متمثلـة في المؤهلات العلميـة للمشاركين في تطبيق البرنامج، الإخلاص في التنفيذ، عدم ذكر مهددات الصدق الداخلي، عدم الالتزام بحساب الثبات المحدد، وعدم وجود رسم بياني. وهي دراسة واحدة لم تتطبق عليها تلك لك لئك

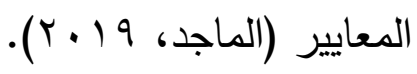


تتوعت أعوام نشر الـ ء ا دراسـة التي اتفقت مـع معـيير المراجعة الحالية، إذ يتضـح أن

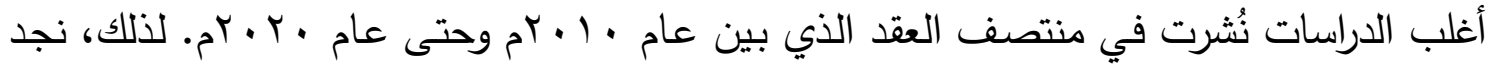

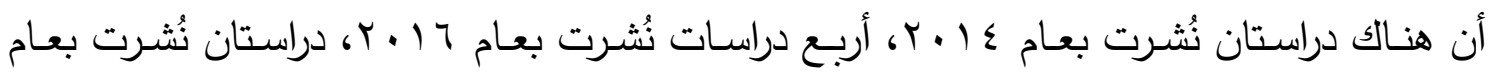

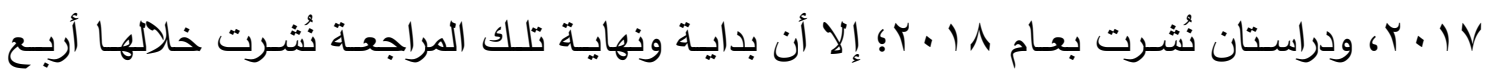

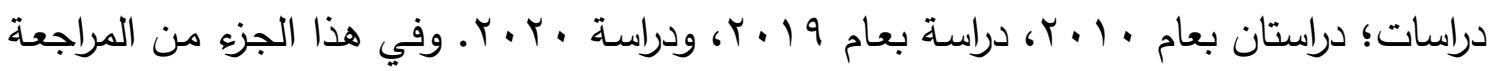
سوف يـتم استعراض النتائج بنـاءً على وصـف المشـاركين، تصـاميم وإجراءات الدراسـة، وصـف التخخلات المُستخدمة واستعراض نتائجها.

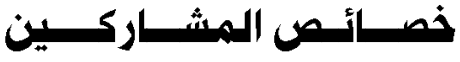

بلغ العدد الاجمالي للمشاركين من الأطفال ذوي اضطراب فرط الحركة وتشتت الانتباه في تلك الدراسات التي رُوجعت ه م طفل، كما هو موضـح في الجدول رقم ه (في الملاحق). وفي هذا الجانب سيتم مُناقشة المرحلة الدراسية للمشاركين، أعمارهم، وجنسه. تراوحت أعمار المشاركين في جميع الدراسـات بين عمر أربع سنوات وحتى ب ا سنة؛ كمـا بلـغ عدد المشـاركين في مرحلة

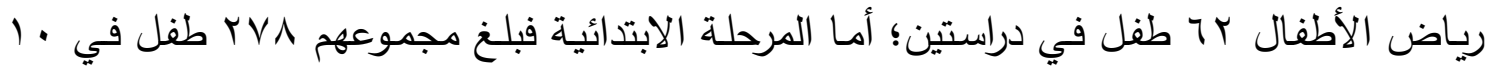
دراسات؛ في حين أن هناك دراستين دمجت بين المرحلتين وتمثل عددهم في هب طفل من مرحلة رياض الأطفال والمرحلة الابتدائية. وفي توضيح لجنس المشاركين في تلك الدراسـات، اتضـح أن الدراسات اشتملت على الذكور والاناث، وعلى الرغم من ذلك فإن التركيز في نصف تلك الدراسات على الذكور تقريبًا بنسبة (979\%)، و( (r\%) على الإناث؛ ففي دراستان كان جميع المشاركين ذكور ، وخمس دراسات الغالبية منهم ذكور، إلا أن هناك دراسة تساوى فيها عدد الذكور مع الاناث؛ في حين لم يحدد البقية من الدراسات (ست دراسات) نوع الجنس الذي اشتملت عليه.

\section{وصسف تصساميسم الـدراسـات}

وفقاً لمعايير التضمين، طبقت جميع الدراسـات المشمولة في هذه الدراسـة تصـيم الثبة تجريبي وتصاميم الحالة الواحدة. أغلب الدراسات في هذه المراجعة المُمنهجة اتبعت تصميم الشبة تجريب؛ حيث إن تسع دراسات من أصل أربعة عشر دراسـة اتبعت تصميم الشبة تجريبي وخمس من هذه الدراسات تصاميم الحالة الواحدة. 
استخدت دراسات المنهج الثبة التجربي في هذه المراجعة تصميم المجموعتين" مجموعة ضـابطة ومجموعـة التـخل"، وتصـميم المجموعـة الواحدة مـع الاختبـار القبلي والبعدي، كمـا هو

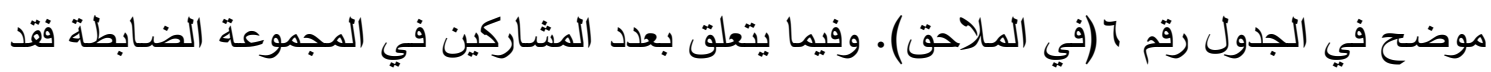
بلغ (VY) مشـارك، ومجموعة التدخل (r • () مشـارك، أمـا الدراسـات ذات المجموعة الواحدة فعدد

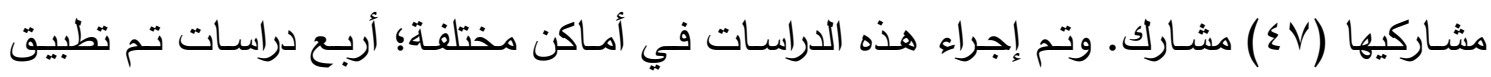
Corkum et Campeño-Martinez et al., التدخل في المدرسة (المعيقل، • ( • ب؟ 2017 Pfiffner et al., 2018 ; al., 2010 (Wilkest-Gillan, 2014; Wilkest-Gillan, 2016)، وهنـاك دراسـة طبقت التدخل في العيادة فقط (Jurjadeh et al., 2018)، ودراسة أخرى طُبقت في مركز تنس الطاولة في الجامعة (Pana et al., 2016)، أما دراسة . Feil et al) (2016) طبقت التدخل في المنزل والمدرسة. وعند الحديث عن القائمين على التدخل في هذه الدراسـات، فقد طبق التدخل الباحثين أنفسهم Jurjadeh et al., 2018;(Wilkes-Gillan et al., )، وفي دراسة) (Pfiffner et al 2018;

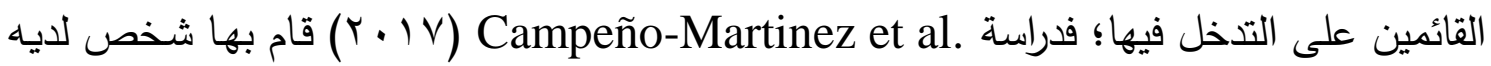
درجة الماجستير في علم النفس تحت أشراف بروفيسور من قسم التربية وعلم النفس، ودراسـة أخرى نفذها طلاب من الدراسات العليا بقسم علم النفس وهي دراسة .Corkum et al ( • ( ب)، ونفذ مدرب أساسي وثمـان مساعدين في البحث ومتخصصين في التربية الخاصـة والتربية البدنية في

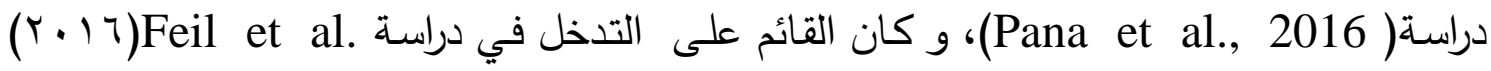

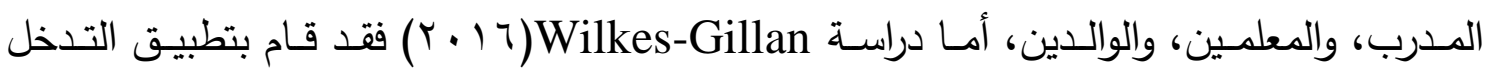
المؤلف الأول"Wilkes-Gillan" وعضو هيئة تدريس وأخصائي لتقييم الأطفال في العيادة على اختبار المرحTOP ـ وبالإضافة للفترة الزمنية للتدخل، فمتوسط مدة التدخل لجميع الدراسات عشرة أسابيع لأربعة وعشرين جلسة بواقع جلستان أو ثلاث جلسات اسبوعياً. ومـن ناحيـة الدراسـات ذات تصــاميم الحالــة الواحـدة فهنـالك دراسـتان اتبعـت تصــيم (ABAB)، ودراسـة استخدمت تصـيم (ABA)، ودراستان استخدمتا تصـميم الخطوط القاعديـة المتعددة، كما هو موضـح في الجدول رقم 7 (في الملاحق). وبلـغ عدد المشاركين في الدراسـات 
ذات تصـاميم الحالـة الواحدة (rr) مشـارك. وفيمـا يـرتبط بموقـع إجراء الدراسـة فهنـالك دراستان تم إجراؤهما في المنزل؛ أما ثلاث (Jijina \& Sinha, 2016 ; Daffner et al., 2020)

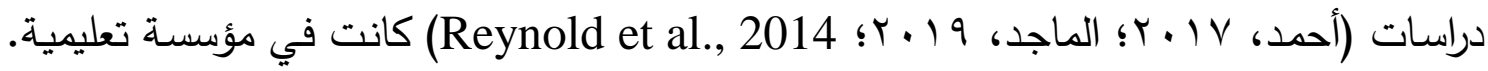
أما القائمين على التدخل في الدراسة، فدراسة الماجد (9 ( ب ) قاما بها المعلم والباحثة؛ بينما دراسة

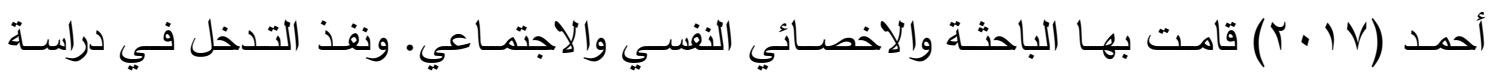
(2020) Daffner et al Reynold et al.

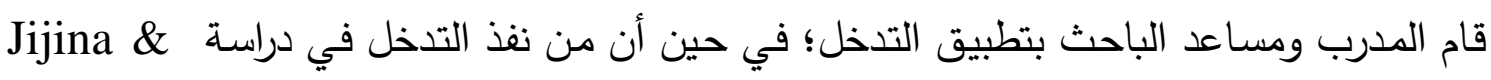
Sinha

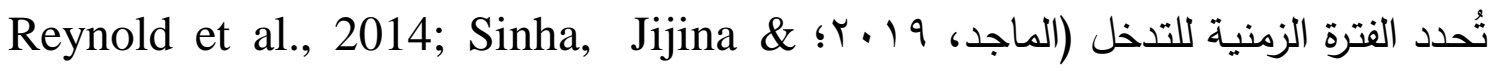
2016) مما يمنع تحديد متوسط مدة التدخل للدراسات، ولكن متوسط عدد الجلسات في الأسبوع للتدخل هو ما يقارب جلستان في الأسبوع.

\section{التـذفلات لتطـويـر المهـارات الاجتمساعيسة}

جاءت التدخلات التربوية في الدراسات التي تتاولتها هذه المراجعة المنهجية متتوعة من حيث نوع التدخل التزبوي والنتائج التي خرجت بها، هذا التتوع يمكن تناوله على النحو التالي: تدخلات تربوية ركزت على اللعب والنثاط البدني في تطوير المهارات الاجتماعية ، حيث تناولت دراسة (الماجد،9 1 •r؛ Wilkes-Gillan et al.,2016; Pana et al.,2016) اللعب كأحد التدخلات التربويـة ، حيث تم اختيار أحد الأنثطة الرياضية، أو تجهيز غرف اللعب حتى يتت

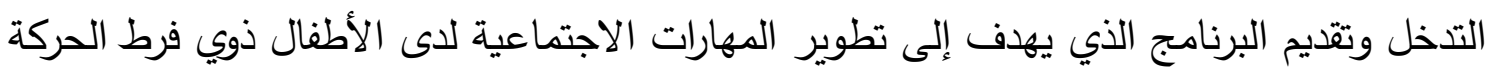

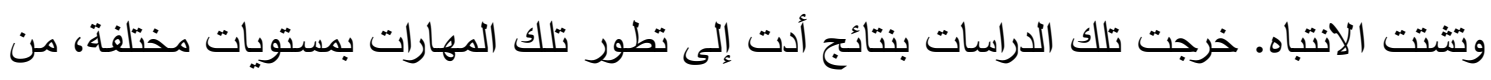
تلك النتائج تحسن في مهارات اللعب بثكل عام، زيادة في المبادرات والتفاعل الاجتماعي بين

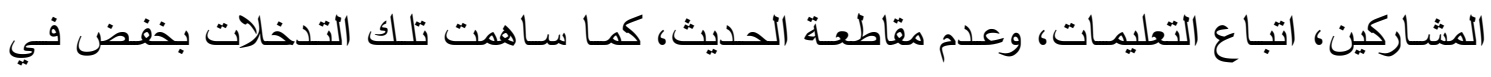
السلوكيات غير المرغوب فيها مثل العدوانية.

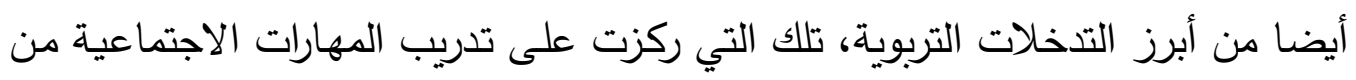

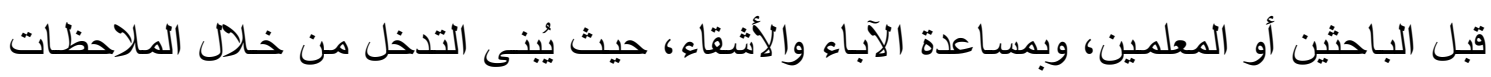


أ / موضي الهويمل \& أ/ نوضاء القحطاني \& أ/ هناء الرويلي تطوير الممارات الاجتماعية للأطفال ذوي فرط الدركة وتشتت الانتباه

الأولية للأطفال فرط الحركة وتثتت الانتباه ثم القيام باستهداف تلك المهارات بالتدريب، جاءت

(Daffner et al., 2020; Jijina \&Sinha, 2016; تلك التدخلات في الدراسات التالية Jurjadeh et al., 2018; Reynolds et al,2014) التـدريب على المهارات الوظيفيـة للأطفـال ذوي فرط الحركـة وتثـتـت الانتبـاه يـؤدي إلى تقليـل

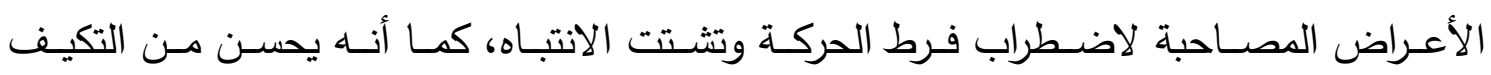
الاجتماعي لهؤلاء الأطفال. سـاهمت هذه التدخلات القائمسة على التدريب في زيـادة السلوكيات الاجتماعية المستهدفة كالمشاركة، المساعدة، المبادرة، التواصل البصري، فهم المشاعر ، كما أنها ساهمت في خفض السلوكيات الاجتماعية السلبية. تأتي البرامج التربويـة كأحد التدخلات التي تم تطبيقها في تطوير المهارات الاجتماعية للأطفال ذوي فرط الحركة وتشتت الانتباه، حيث تم تطبيق برامج تربوية مصدمة لاستهداف مهارات

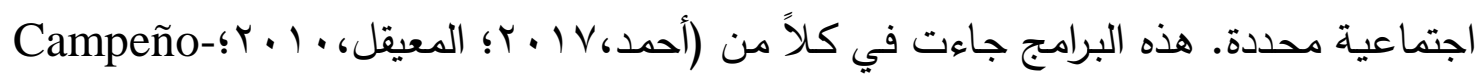
Martínez et al. 2017 ; Corkum et al.,2010;Feil et al.,2016 ;Pfiffner et al. 2018 ; Wilkes-Gillan et al., (2014;. كالمحادثة، المساعدة، المشاركة، كما تناولت برنامج يستهدف تحقيق التعاون بين الطلاب والآباء والمعلمين للوصول إلى أفضل النتائج؛ برنامج الإدارة الذاتية لزيادة التفاعل الاجتماعي؛ وبرنامج

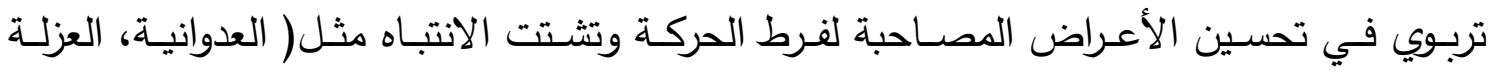

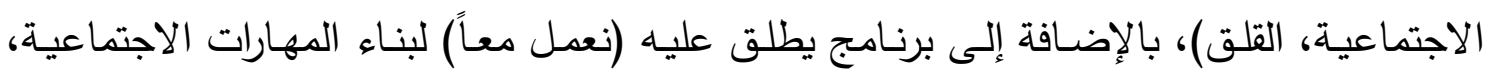

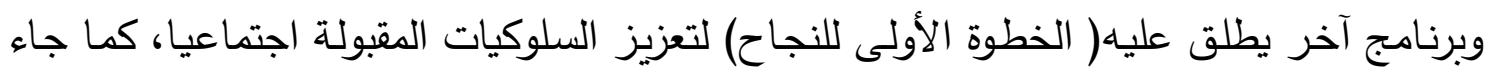

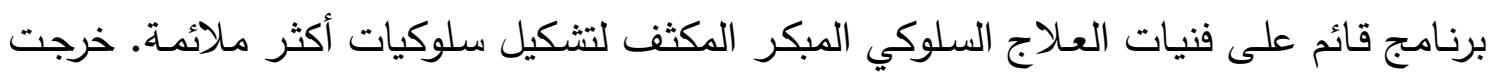
تلك البرامج التي هدفت إلى تطوير المهارات الاجتماعية بنتائج منها، أن تلك المهارات المستهدفة سجلت نتائج إيجابية لدى الأطفال ذوي فرط الحركة وتثتت الانتباه، كما خرجت بتحسن ملحوظ

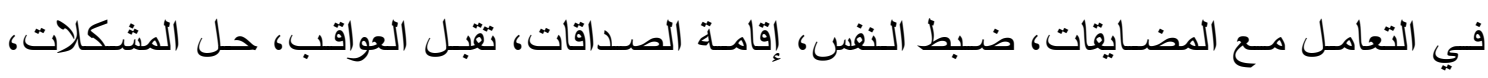
بالمقابل ساهدت هذه البرامج التربوية في خفض السلوكيات غير المقبولة اجتماعياً، كالعدوانية، العزلة الاجتماعية، كما خرجت أيضا بنتائج ثانوية كتحسن الأداء الأكاديمي، وأن التحسن في اللغة البراغماتية يعطي تتبأ بتحسن في المهارات الاجتماعية. 


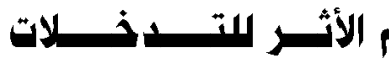

من خـلال احتساب حجم الأثر برز عدد من البرامج بواسطة تسبلها حجم أثر كبير

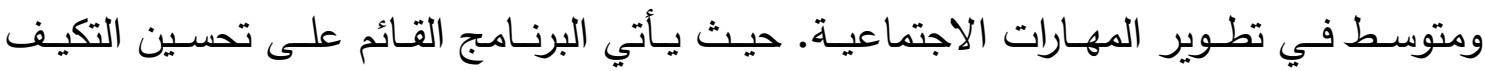
الاجتماعي، البرنامج السلوكي القائم على خفض السلوك الاندفاعي وزيادة التفاعل الاجتماعي وتكوين العلاقات، التدخل القائم على تدريب التفاعل بين الأقران، والتدخل القائم على تدريب

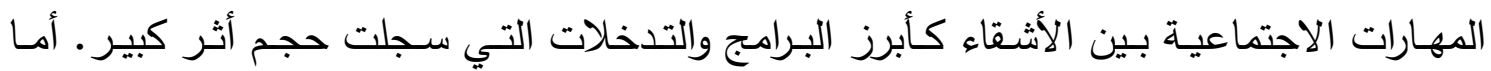
التدخلات التي سجلت حجم أثر متوسط في تطوير المهارات الاجتماعية فتمثلت في برنامج تدريبي قائم على تحسين المهارات الحياتية، وبرنامج تربوي لتحسين الأعراض المصاحبة لاضطراب فرط الحركة وتشتت الانتباه (العزلة الاجتماعية والعدوانية).

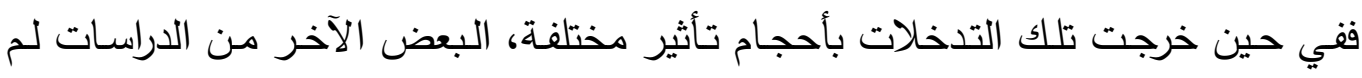
تذكر حجم تأثير تلك التدخلات. التدخلات التي سجلت حجم تأثير جاءت في الدراسات التالية؛

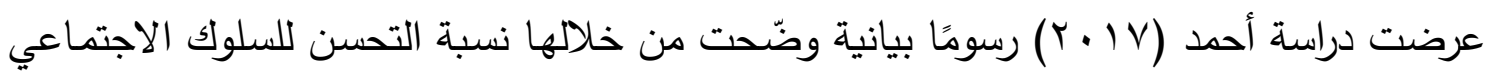

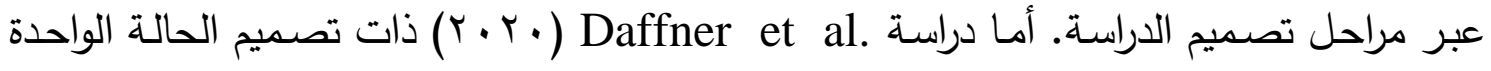
أيضـا وضحت حجم الأثر لبرنامج التدخل باستخدام التحليل البصري للبيانات المعروضـة لتقييم

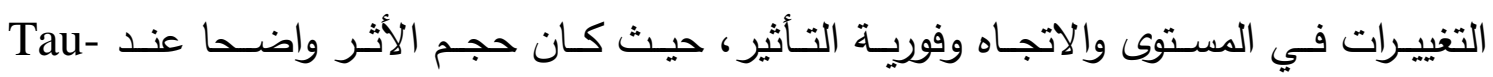
داس U=0.9531. وفي الدراسات التي اتبعت المنهج الثبه تجريبي فكان حجم الأثر متفاوت؛ ففي واطي

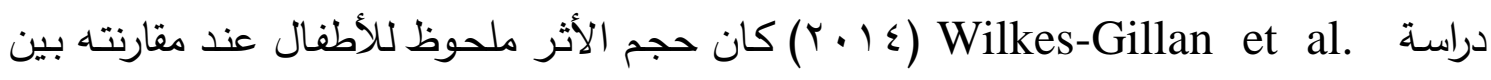

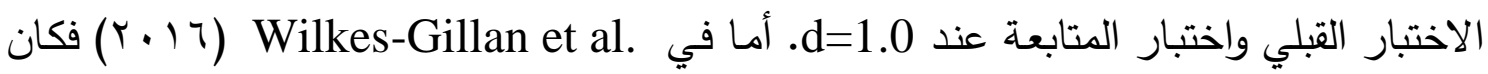

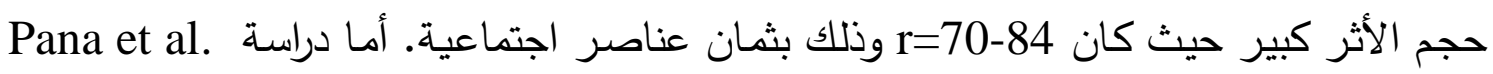

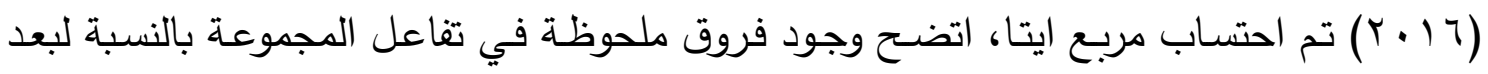

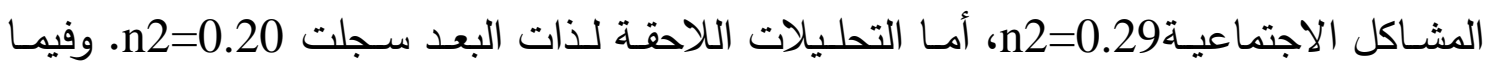

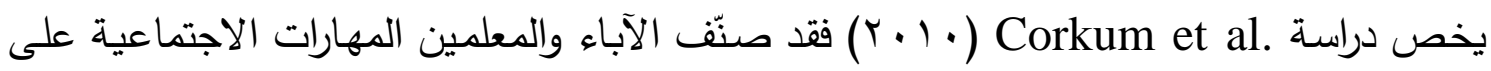
أنها أعلى بكثير عند حساب التقييم البعدي P=.04 للمعلمين، 05=05 للآباء. وبالنسبة لدراسة 1 Pfiffner et al.

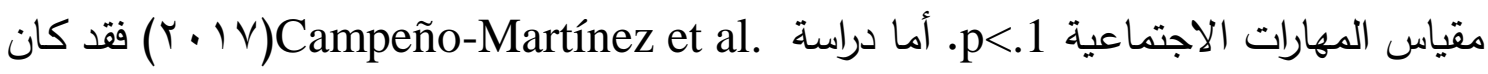


حجم الأثر للتدخل متوسط، حيث سجل 35.r. أمـا آخر الدراسـات الثبه تجريبية، هي دراسـة إض Jurjadeh et al.

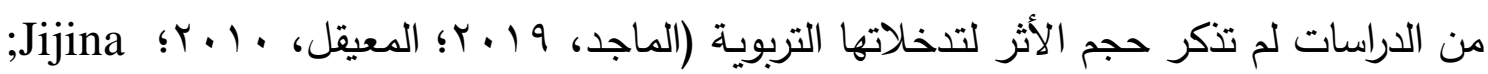
.(Reynolds et al. ,2014 \&Sinha,2016

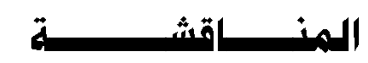

هدفت المراجعـة المنهجيـة الحالية إلى فحص الدراسـات التي تتاولت التدخلات والبرامج التربويـة التي قد تسـاهم في تطوير المهارات الاجتماعيـة للأطفال ذوي اضطراب فرط الحركـة

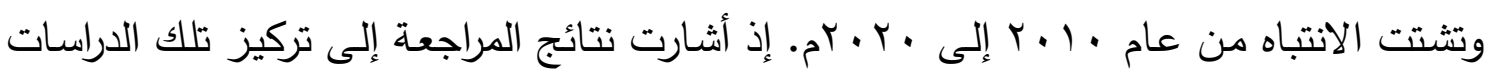

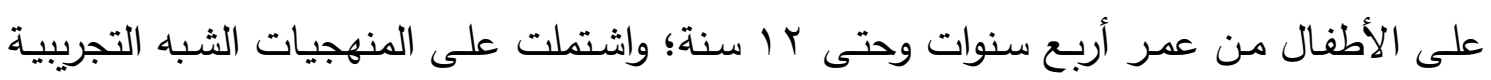
وتصـاميم الحالـة الواحدة، استندت تلك الدراسـات على التدخلات المستندة على اللعب والنشـاط البدني؛ التدخلات المُركزة على تدريب المهارات الاجتماعية من قبل المعلمين، الآباء، والأشقاء؛ وكذلك البرامج التربوية المصممة لمعالجة وتطوير مهارات اجتماعية مُحددة لذوي اضطراب فرط الحركة وتثتت الانتباه.

تقترح تلك الدراسات فائدة التدخلات والبرامج التربوية في تطوير ورفع مستوى المهارات الاجتماعية المقبولة كالتفاعل الاجتماعي، وزيادة المبادرات، كما أدت كذلك إلى خفض السلوكيات

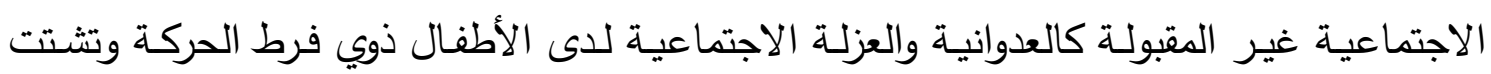
الانتباه. وعلى الرغم من ذلك، إلا أن الدراسات - وفقًا للمراجعة الحالية- اليُطبقة على الأطفال ذوي فرط الحركـة وتثتت الانتباه مـاتزال قليلـة لفحص فعاليـة التدخلات التي تستهدف تطوير المهارات الاجتماعية باستخدام التصـاميم الثبا تجريبية وتصـاميم الحالة الواحدة؛ هذا إلى جانب اختلاف تصميم التدخل أو البرنامج المُنفذ في تلك الدراسات، مما يخلق الحاجة إلى اجراء المزيد

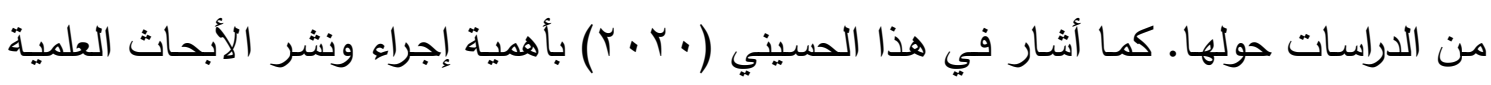
ذات الجودة، وأثر ذلك مع مرور الوقت في تأسيس قاعدة بيانات علمية تشتمل على الأبحاث التي يمكن من خلالها استخلاص الممارسات الفعالة المستتدة على أساس علمي. 
جاءت الدراسات التي تتاولت اللعب كتدخل لتطوير المهارات الاجتماعية للأطفال ذوي فرط الحركة تثتت الانتباه في ثـلاث دراسات وهي (الماجد،9 19 بـ؛ Pana et al.,2016) (Wilkes-Gillan et al.,2016.

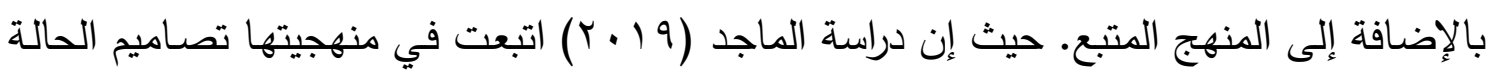

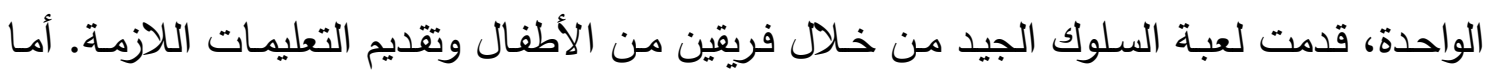
دراستي ( Wilkes -Gillan et al.,2016; Pana et al.,2016) تتشابه من حيث المنهج الشبه

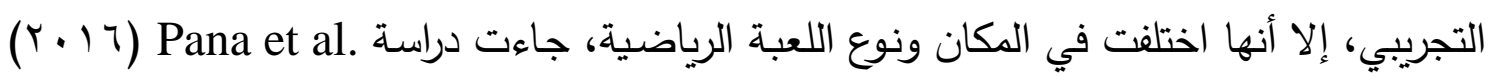

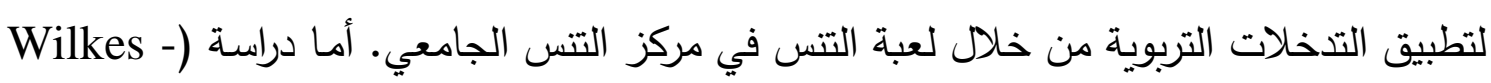

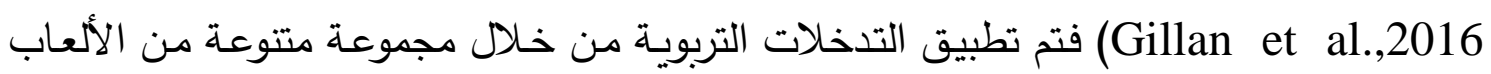
(طوق كرة السلة، ومجموعة البولينج، وألعاب الكرة والمضرب، والسيارات، والتماثيل، ومسدسات،

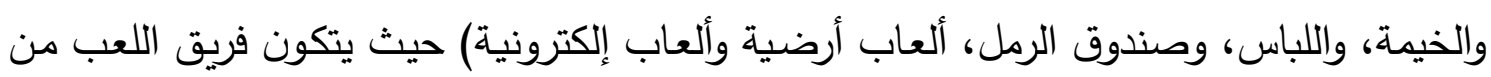
اثثين من الأطفال ذوي اضطراب الحركة وتشتت الانتباه. من النتائج التي خرجت بها المراجعة الحالية تلك التدخلات التربوية التي تقدم تدريبا قائما على استهداف مهارات محددة، ويأتي هذا التدريب من قبل الباحثين، المعلمين، الآباء أو الأشقاء. (Daffner et al., 2020; Jijina\&Sinha,2016; Jurjadeh et al., من خلاءل هذه الدراسات 2018; Reynolds et al,2014) (تخذت المنهج الثبه تجريبي. وفيما يتعلق بطبيعة التدخلات جاءت

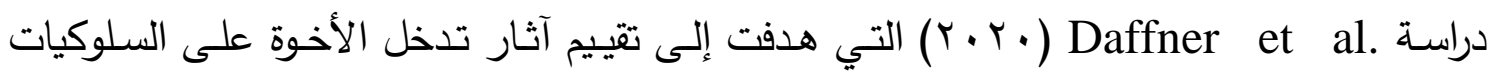
الاجتماعية الإيجابية والسلبية للأطفال الصغار ذوي اضطراب فرط الحركة ونقص الانتباه، وخلال

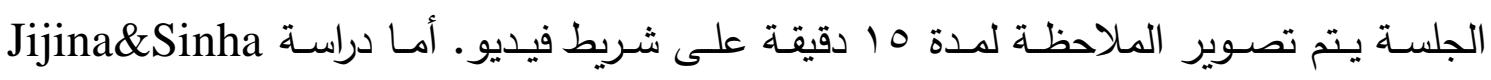

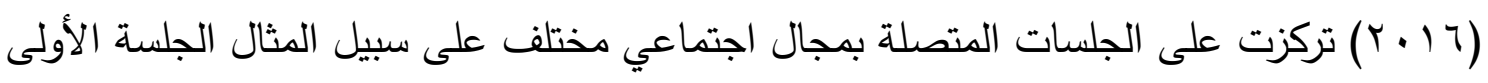

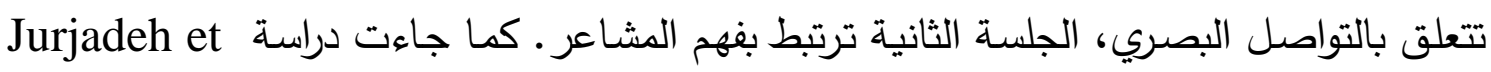

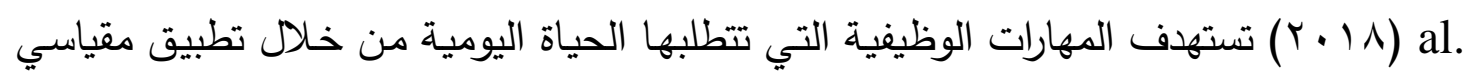

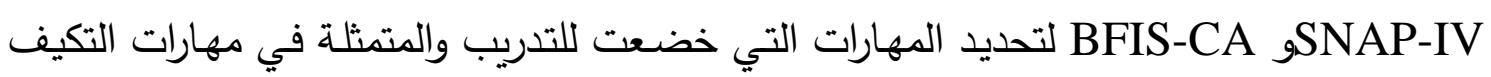

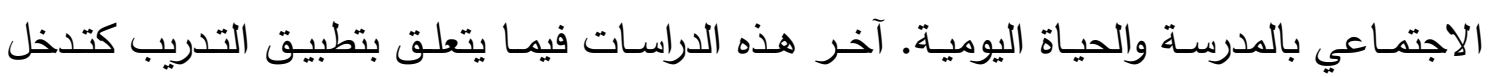


لتطوير المهارات الاجتماعية هي دراسة . Reynolds et al ( ا • ب) التي ركزت على تدريب الإدارة الذاتية من خلال جلسات فردية تضمنت الجلسة التدربية المكونات التالية: (أ) تقديم تعريف للسلوك المستهدف، (ب) تعليم المشاركين استخدام الجهاز، (ج) تعليم الطلاب التسجيل الذاتي، درديه • (د) لعب الأدوار

وفي نفس السياق، اتفقت جميع الدراسات في المراجعة الحالية التي تناولت البرامج التربوية

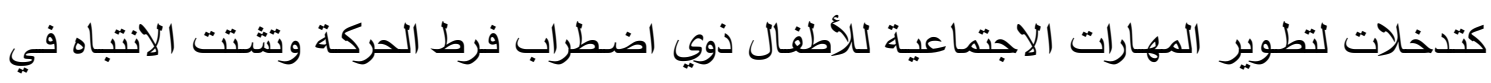

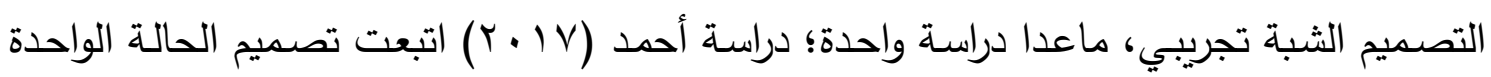

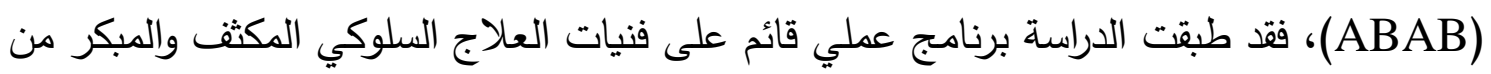
خلال تقنيات تثكيل السلوك لسلوكيات أكثر ملائمة، وأكثر تماشيًا مع ما هو متوقع منه ومن عمره

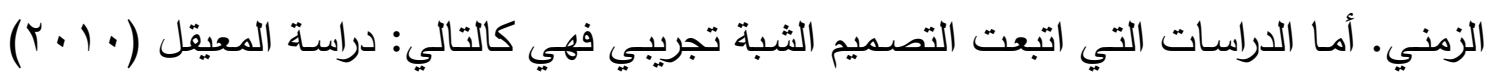

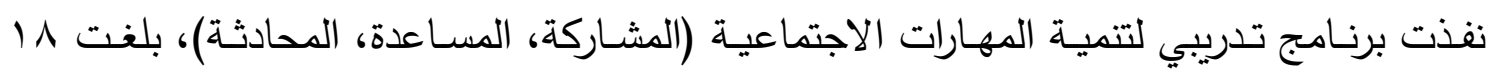
جلسة. وطبقت دراسة (Corkum et al., 2010) برنامج (نعمل معاً) لبناء المهارات الاجتماعية. حيث يشارك طلاب المجموعة في عشر جلسات أسبوعية وفي نهاية كل جلسة أسبوعية، يتم تزويد

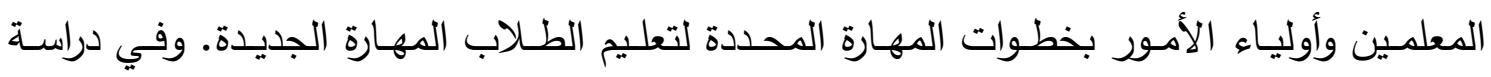
نفذت كل جلسة في العيادة، بدعوة الثنائي" طفل ذوي اضطراب فرط الحركة وتشتت الانتباه وإحدى أقرانه" للعب في غرفة تحتوي على مرآة ذات اتجاه

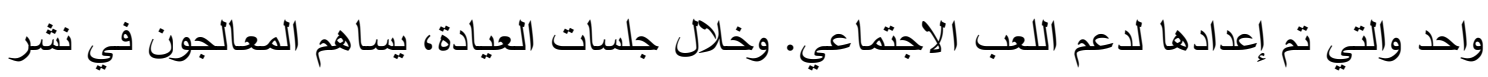

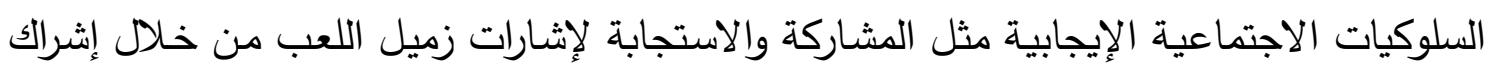
الأطفال في اللعب الاجتماعي المتبادل، واستخدم المعالجون أيضًا عبارات أساسية أثناء وجودهم

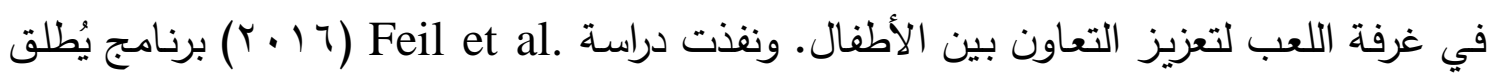
عليه الخطوة الأولى للنجاح، يهدف إلى تعزيز السلوك الإيجابي كاتباع قواعد الصف، التهنئ التعاون،

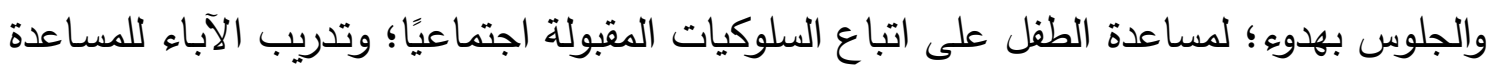

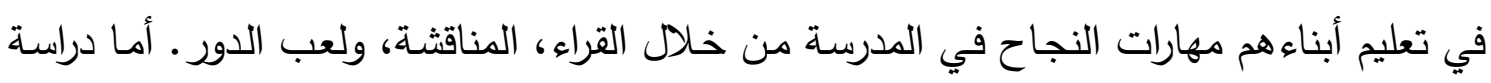
(Campeno-Martinez et al., 2017) الأعراض المصاحبة لدى الأطفال فيما يتعلق بالعدوانية والعزلة الاجتماعية، والقلق ونقص الانتباه. 
وكذلك دراسة (Pfiffner et al., 2018) طبقت برنامج تحسين مهارات التعاون الحياتية بين كلا

$$
\text { من (الطلاب، الآباء، المدرسون). }
$$

من المُلاحظ أن أغلب الدراسات السابقة قام بها أكثر من مؤلف واحد، كما طُبقت من قبل الخبل

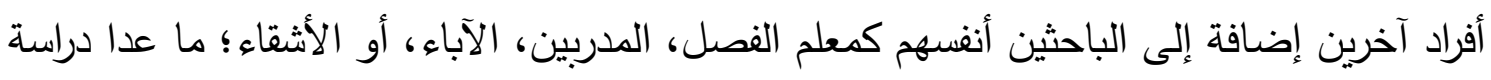

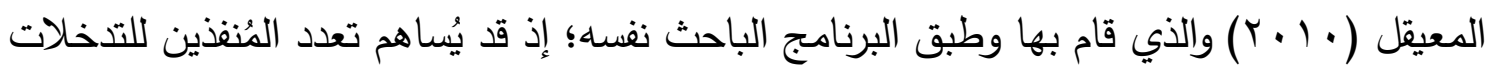
والبرامج تحقيق الموضوعية وتقليل خطر التحيّز في تلك الدراسات. وفي الجانب الآخر فإن تكرار لياري تطبيق البرامج من قبل نفس المؤلف كما في (Wilkes-Gillan et al., 2014, 2016) قد يرفع من خطر التحيّز (Makel et al., 2012). من خلال نتائج المُراجعة الحالية، يتضح أيضًا بروز عدد من الجوانب التي ركزت عليها

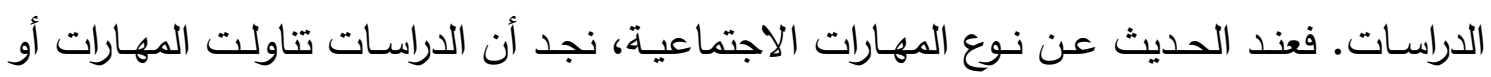

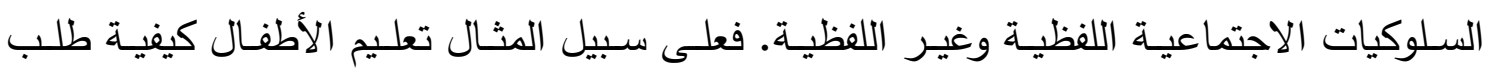

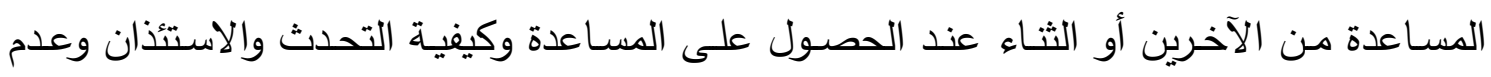
مقاطعة حديث الأخرين. وفيما يتعلق بالمهارات الاجتماعية غير اللفظية من خلال تدريبهم على ولى

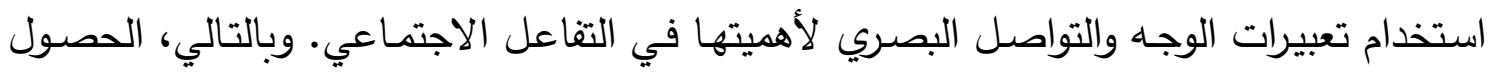
على سلوكيات ومهارات اجتماعية مقبولة اجتماعياً وخفض السلوكيات غير المقبولة في المجتمع.

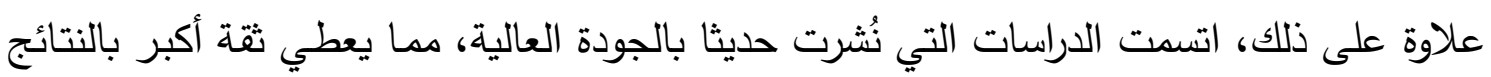

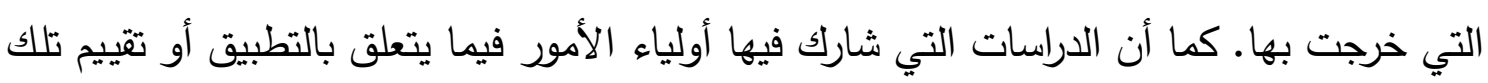
البرامج أعطت نتائج واضحة عن تلك المهارات الاجتماعية التي تم تطويرها.

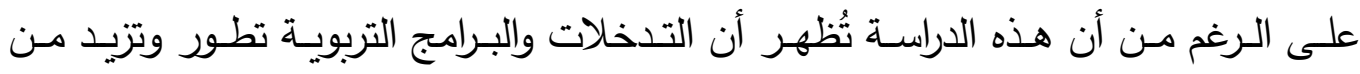

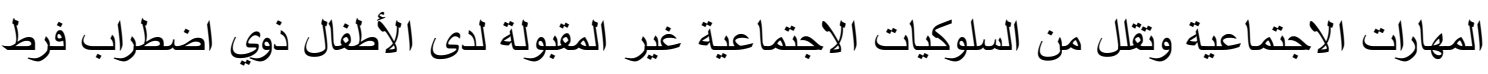
الحركة وتثتت الانتباه، إلا أنه يجب مراعاة العديد من القيود عند تفسير نتائج هذه المراجعة. فلقد تم التمبئ

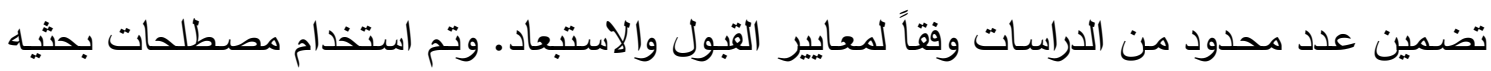
وقواعد بيانات إلكترونية محددة. بالإضافة إلى ذلك، لم نقم بتضمين الرسائل والدراسات غير المنشورة

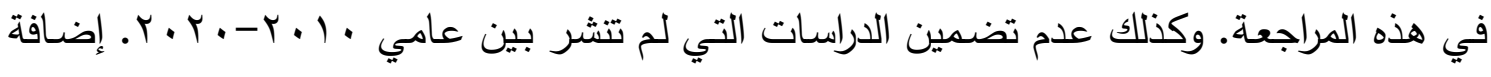


إلى عدم تضمين دراسات عالمية بلغات أخرى نظراً لصعوبة الترجمة مما قد يحد من النتائج. أيضاً بعض الدراسات لم تحقق معايير جودة عالية طبقاً لمعايير CEC. واستبعاد الدراسات غير المتعلقة

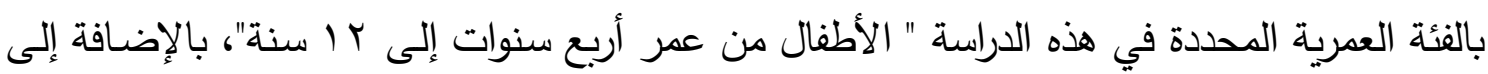
استبعاد دراسات لم تستخدم تصميم الثبة التجريبي أو تصاميم الحالة الواحدة.

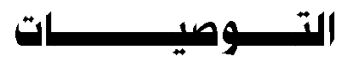

بناءً على نتائج المراجعة الحالية، فإنه يجدر بنا الخروج بعدد من المقترحات والتوصيات على الصعيد النظري والتطبيقي. إذ قد يكون لهذا البحث آثار مستقبلية فيما يتعلق بإعطاء المزيد

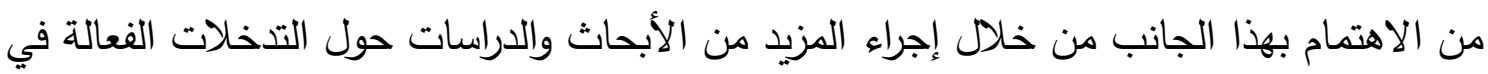

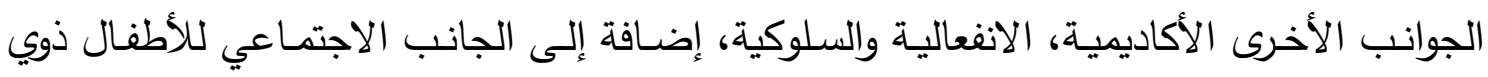
اضطراب فرط الحركة وتشتت الانتباه؛ باستخدام منهجيات بحثية ثُراعي في ذلك معايير الجودة. أما فيما يخص الجانب التطبيقي أو الميداني، فإن نتائج الدراسة الحالية تدعوا المسؤولين والقائمين

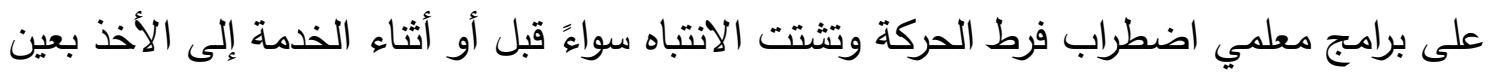

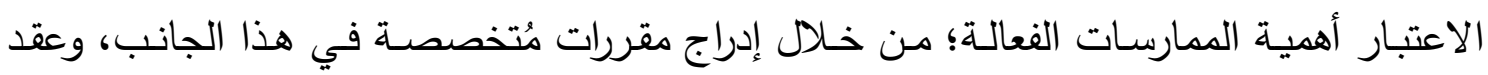
الدورات التدريبية وورش العمل المُسـاهمة في صقل مهارات المعلمين لتطبيق التدخلات الفعالـة

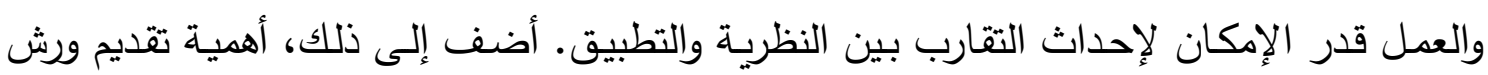
العمل والدورات التدريبية الموجهة للأسر ، والتي توضح من خلالها آلية تطبيق الممارسات الفعالة لتطوير المهارات الاجتماعية أثناء تعاملهم مع أبنائهم، ويراعى أثناء التخطيط لتلك الدورات والبرامج

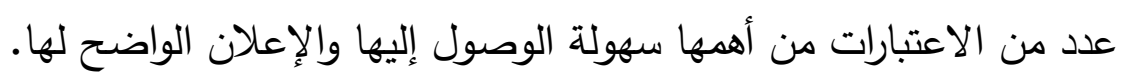

جاءت هذه المراجعة المنهجية الحالية لتحديد أبرز التدخلات التربوية التي من شأنها أن تساهم في تطوير المهارات الاجتماعية للأطفال ذوي اضطراب فرط الحركة وتشتت الانتباه، كما لـاهي أن هذا التحديد يساعد المعلمين والمربين في اختيار أفضل التدخلات التربوية وتطبيقها مع الأطفال ذوي اضطراب فرط الحركة وتشتت الانتباه. أبرز ما خرجت به هذه المراجعة من حيث التدخلات

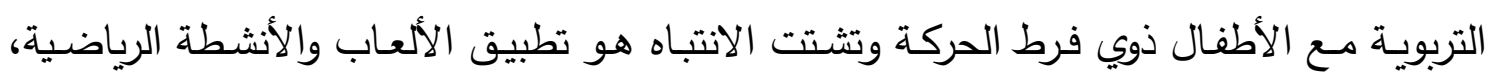


تطبيق البرامج التربوية، التدريب على المهارات الاجتماعية. ذكر .Gough et al (7 ( • ) أن

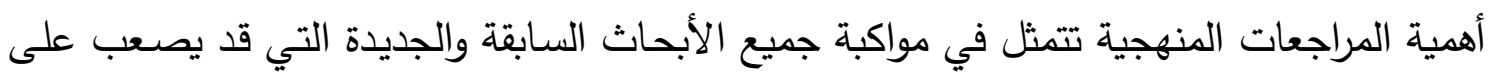
الفرد تتبعها، كما أن نتائج المراجعة توفر سياق لتفسير نتائج تلك الدراسات الأولية التي يتم تتاولها من خلال المراجعة المنهجية.

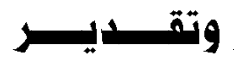

تتقدم الباحثات بوافر الثكر والتقدير للدكتورة الفاضلة أماني سلمان السلمان نظير إشرافها وتقديمها الملاحظات المُساهمة في تجويد العمل؛ كما نُقدم الامتتان والثُكر الجزيل لجامعة الملك سعود على إتاحة الفرصة للاستفادة من قواعد البيانات. 


\section{المهـــاجــــــ}

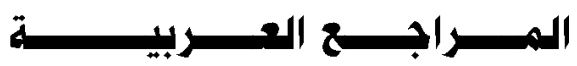

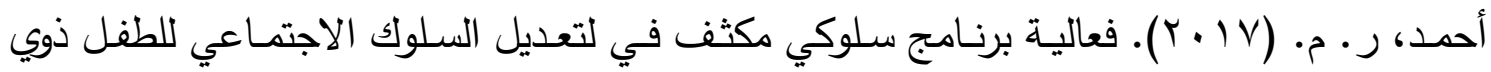

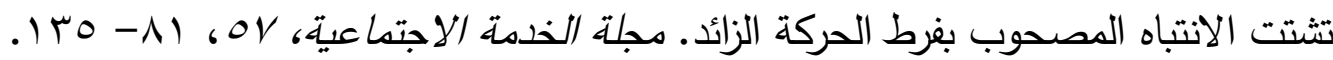
https://search-mandumah-com.sdl.idm.oclc.org/Record/864466 الحسيني، ع. ( • • (Y). مؤشرات جودة مناهج البحث في التربية الخاصـة: المدارسات المستندة إلى البراهين. مركز الملك سلمان لأبحاث الإعاقة.

الماجد، م. (9 ( • ( ). فاعلية لعبة السلوك الجيد في تحسين السلوكيات الاجتماعية لدى الأطفال

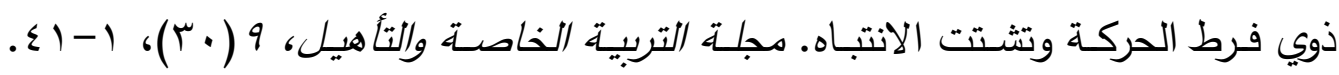
https://search-mandumah-com.sdl.idm.oclc.org/Record/994932 المعيقل، أ. ( • ( • ). فعاليـة برنـامج تدريبي باسـتخدام الأنشطة اللاصـفية في تتميـة المهارات الاجتماعية لدى التلاميذ ذوي اضطراب ضـف الانتباه والنشـاط الحركي المفرط. مجلة

$$
\text { كلية التربية، ا (ع r)، }
$$

مطر ،ع. والجمال، ر. (1 ( • r). فعالية برنامج تدربي مهارات إدارة الذات في خفض اضطراب اللغـة البراجماتية لدى الأطفال ذوي اضطراب فرط الحركة وتثتت الانتباه. مجلة كلية

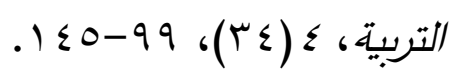

http://search.mandumah.com/Record/106334

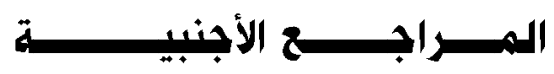

American Psychiatric Association (APA). (2013). Diagnostic and Statistical Manual of Mental Disorders, Fifth Edition. https://images.pearsonclinical.com/images/assets/basc3/basc3resources/DSM5_DiagnosticCriteria_ADHD.pdf Asghari, A., \& Basiri, E. (2019). Canonical analysis of the association between attention-deficit/hyperactivity disorder with some psychological problems among students. International Journal of Psychology and Educational Studies, 6(1), 21-29. 
Bronson, D. E., \& Davis. T. S. (2012). Finding and evaluation evidence: Systematic reviews and evidence-based practice. Oxford University Press.

Boland, A. Cherry, M. G. Dickson, R. (2017). Doing a systematic review, a student guide. SAGE Publication Ltd.

Campeño-Martínez, Y. Santiago-Ramajo, S. Asencio,E. VergaraMoragues, E. Bermejo, V. (2017). Efficacy of an intervention program for attention and reflexivity in children with attention deficit hyperactivity disorder. Mind, brain and education, 11(2) 64-74

Cleminshaw, C. L., DuPaul, G. J., Kipperman, K. L., Evans, S. W., \& Owens, J. S. (2020). Social deficits in high school students with attention-deficit/hyperactivity disorder and the role of emotion dysregulation. School Psychology, 35(4), 233.

Corkum, P. Corbin, N. Pike, M. (2010). Evaluation of a school-based social skills program for children with attention-deficit/hyperactivity disorder. Child \& Family Behavior Therapy,32(2),139-151.

Council for Exceptional Children. (2014). Council for exceptional children standers for evidence-based practices in special education.

Daffner, M. S., DuPaul, G. J., Kern, L., Cole, C. L., \& Cleminshaw, C. L. (2020). Enhancing social skills of young children with ADHD: Effects of a sibling-mediated intervention. Behavior Modification, 44(5), 698-726.

https://doi.org/10.1177/0145445519843473

Ellis, B. M. (2016). Attention-deficit/hyperactivity disorder symptoms as a mediator of the relation between social perception and social skills and adaptability in preschoolers (Puplication No. 10102771) [ Master Theses, The University of Southern Mississippi]. ProQuest Dissertations \& Theses Global. https://search-proquest-com.sdl.idm.oclc.org/docview/ $\underline{1786672687 \text { ? accountid }=142908}$ 
أ / موضي الهويمل \& أ/ نوضاء القحطاني \& أ/ هناء الرويلي تطوير الممارات الاجتماعية للأطفال ذوي فرط الدركة وتشتت الانتباه

Every Student Succeeds Act (ESSA). (2015).Every Student Succeeds Act (ESSA) | U.S. Department of Education

Feil, E. G., Small, J. W., Seeley, J. R., Walker, H. M., Golly, A., Frey, A., \& Forness, S. R. (2016). Early intervention for preschoolers at risk for attention-Deficit/Hyperactivity disorder: Preschool first step to success. Behavioral Disorders, 41(2), 95-106.

http://dx.doi.org.sdl.idm.oclc.org/10.17988/0198-7429-41.2.95

Gough, D. Oliver, S. Thomas, J. (2016). An introduction to systematic reviews. Sage.

Grygiel, P., Humenny, G., Rębisz, S., Bajcar, E., \& Switaj, P. (2018). Peer rejection and perceived quality of relations with schoolmates among children with ADHD. Journal of Attention Disorders, 22(8), 738751. https://doi.org/10.1177/1087054714563791

Individual with Disabilities Education Act, 114-95 $§ 300.101(2004)$. https://sites.ed.gov/idea/regs/b/b/300.101

Jijina, P., \& Sinha, U. K. (2016). Parent assisted social skills training for children with attention deficit hyperactivity disorder. Journal of the Indian Academy of Applied Psychology, 42(2), 299-309.

https://search-proquest-com.sdl.idm.oclc.org/docview/ $\underline{1834883673 \text { ? accountid }=142908}$

Jurjadeh, S. Mashhadim A. Tabibi, Z. Kheirkhah, F. (2018). Effect of daily life executive functions training on symptoms and adaptive skills in children with attention deficit/ hyperactivity disorder. Journal of Research \& Health, 8(3), 269-277

Kats-Gold, I., \& Priel, B. (2009). Emotion, understanding, and social skills among boys at risk of attention deficit hyperactivity disorder. Psychology in the Schools, 46(7), 658-678. 
Kearney, D. S., \& Healy, O. (2011). Investigating the relationship between challenging behavior, co-morbid psychopathology, and social skills in adults with moderate to severe intellectual disabilities in Ireland. Research in Developmental Disabilities, 32(5), 1556-1563.

Makel, M. C., Plucker, J. A., \& Hegarty, B. (2012). Replications in psychology research: How often do they really occur? Perspectives on Psychological Science, 7(6), 537-542. https://doi.org/10.1177/1745691612460688

Mikami, A. Smit, S. Khalis, A. (2017). Social skills training and ADHDwhat works?. Current psychiatry reports, 19(12),1-9

Morrin, S. Sheen, J. Ling, M. Foly, D. Sciberras, E. (2020). Interventions for adolescents with ADHD to improve peer social functioning: A systematic review and Meta-Analysis. Journal of Attention Disorders,1-18. https://doi-org.sdl.idm.oclc.org/10.1177/1087054720906514

Pan, C., Chu, C., Tsai, C., Lo, S., Cheng, Y., \& Liu, Y. (2016). A racketsport intervention improves behavioral and cognitive performance in children with attention-deficit/hyperactivity disorder. Research in Developmental Disabilities, 57, 1-10. http://dx.doi.org.sdl.idm.oclc.org/10.1016/j.ridd.2016.06.009

Pelham, W. E., Gnagy, E. M., Greiner, A. R., Hoza, B., Hinshaw, S. P., Swanson, J. M., Simpson, S. S., Shapiro, C., Bukstein, O., BaronMyak, C. \& McBurnett, K. (2000). Behavioral versus behavioral and pharmacological treatment in ADHD children attending a summer treatment program. Journal of abnormal child psychology, 28(6), 507-525. 
Pfiffner, L. Rooney, M. Jiang,Y. Haack, L. Beaulieu, A. McBurnett, K. (2018). Sustained effects of collaborative school-home intervention for ADHD symptoms and impairment. Journal of the American Academy of Child and Adolescent Psychiatry, 57, 245-251.

Preston, A. S., Heaton, S. C., McCann, S. J., Watson, W. D., \& Selke, G. (2009). The role of multidimensional attentional abilities in academic skills of children with ADHD. Journal of Learning Disabilities, 42(3), 240-9.

http://dx.doi.org.sdl.idm.oclc.org/10.1177/0022219408331042

PRISMA. (2009). Preferred reporting items for systematic reviews and meta-analyses checklist.

Reynolds, B. M., Gast, D. L., \& Luscre, D. (2014). Self-Management of social initiations by kindergarten students with disabilities in the general education classroom. Journal of Positive Behavior Interventions, 16(3), 137-148.

https://doi.org/10.1177/1098300713483176

Smetana, R. (2020). The role of negative parent and teacher perceptions of social competence in children with ADHD (Publication No. 27547737) [ Doctoral dissertation, Adler University]. ProQuest Dissertations \& Theses Global. https://search-proquestcom.sdl.idm.oclc.org/docview/2445583622?accountid=142908

Thapar, A., Holmes, J., Poulton, K., \&Harrington, R. (1999). Genetic basis of attention deficit and hyperactivity. British Journal of Psychiatry, 174, 105-111.

Thomaidis, L., Choleva, A., Janikian, M., Bertou, G., Tsitsika, A., Giannakopoulos, G., \& Anagnostopoulos, D. C. (2017). Attention deficit/hyperactivity disorder (ADHD) symptoms and cognitive skills of preschool children. Psychiatrike, 28(1), 28-36.

http://dx.doi.org.sdl.idm.oclc.org/10.22365/jpsych.2017.281.28 
Thomas, R., Sanders, S., Doust, J., Beller, E., \& Glasziou, P. (2015). Prevalence of attention-deficit/hyperactivity disorder: A systematic review and meta-analysis. Pediatrics, 135(4), 994-1001. http://dx.doi.org.sdl.idm.oclc.org/10.1542/peds.2014-3482

Tseng, W. L., \& Gau, S. S. F. (2013). Executive function as a mediator in the link between attention-deficit/hyperactivity disorder and social problems. Journal of Child Psychology and Psychiatry, 54(9), 9961004.

Wilkes-Gillan, S., Bundy, A., Cordier, R., \& Lincoln, M. (2014). Evaluation of a pilot parent-delivered play-based intervention for children with attention deficit hyperactivity disorder. The American Journal of Occupational Therapy, 68(6), 700-9.

https://search-proquest-com.sdl.idm.oclc.org/docview/ 1628685639 ?accountid $=142908$

Wilkes-Gillan, S., Bundy, A., Cordier, R., Lincoln, M., \& Yu-Wei, C. (2016). A randomized controlled trial of a play-based intervention to improve the social play skills of children with attention deficit hyperactivity disorder (ADHD). PLoS One, 11(8).

http://dx.doi.org.sdl.idm.oclc.org/10.1371/journal.pone.0160558 
أ / موضي الهويمل \& أ/ نوضاء القحطاني \& أ/ هناء الرويلي تطوير المهارات الاجتماعية للأطفال ذوي فرط الحركة وتشتت الانتباه

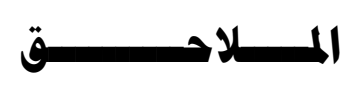

جــــــ (1)

نموذج للتدقق من توافق الدراسات مع معايير القبول المُحدة

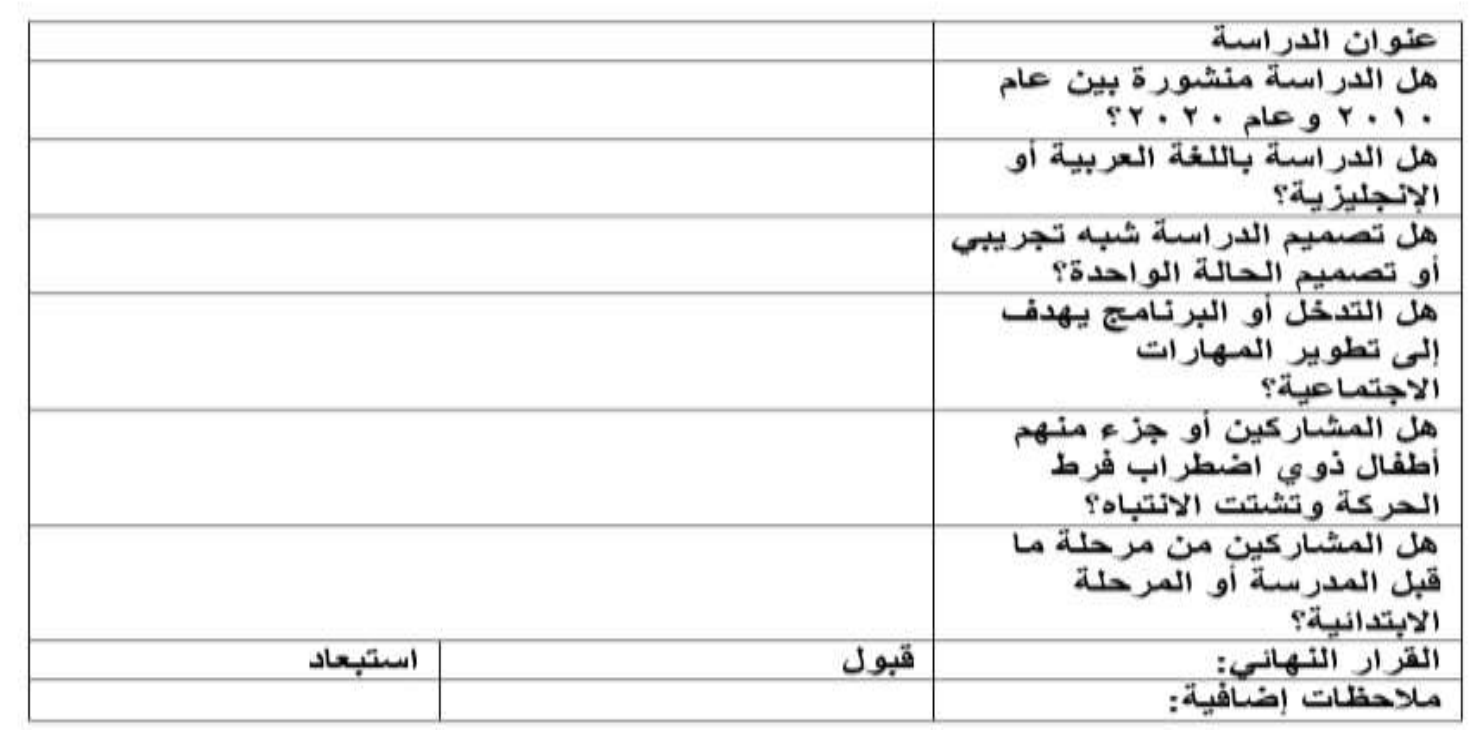

جـــــــ (r)

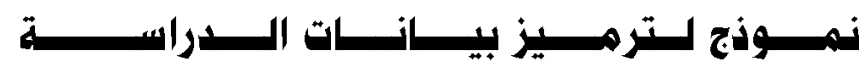

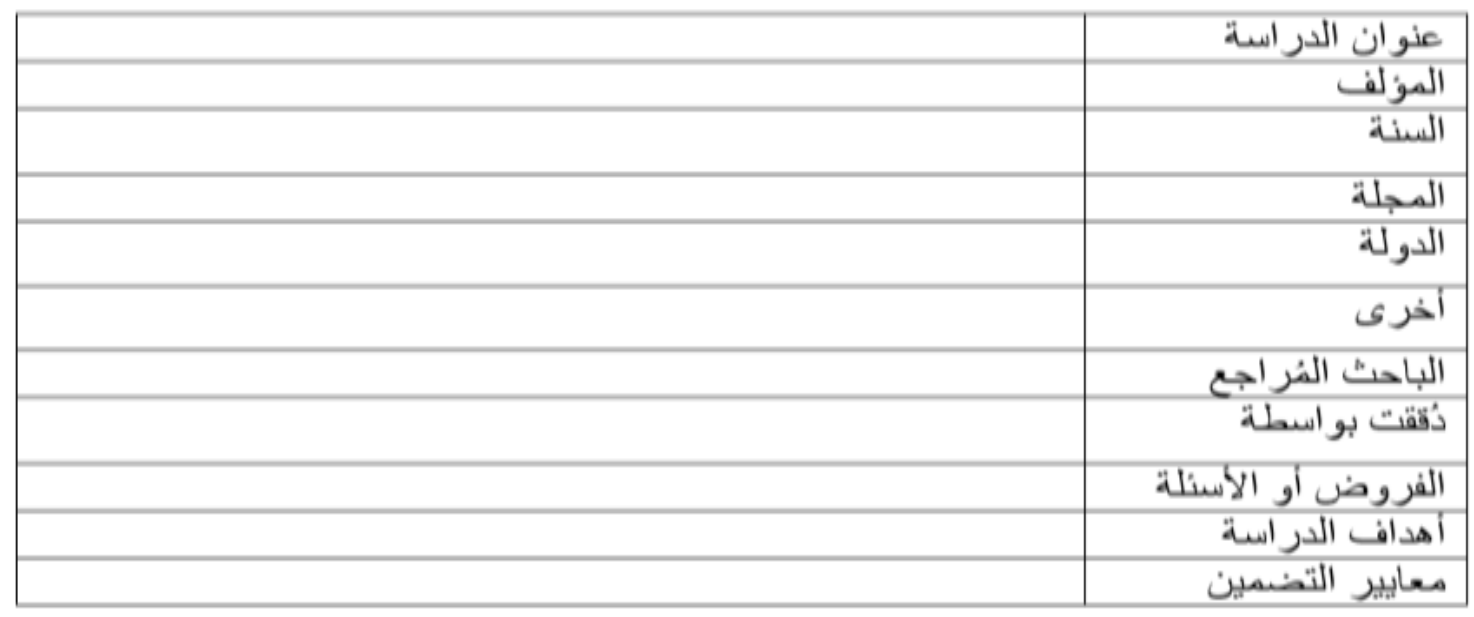




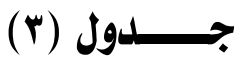

\section{نموذج لترميز بيانات الدراسة بالاعتماد على (PICOS)}

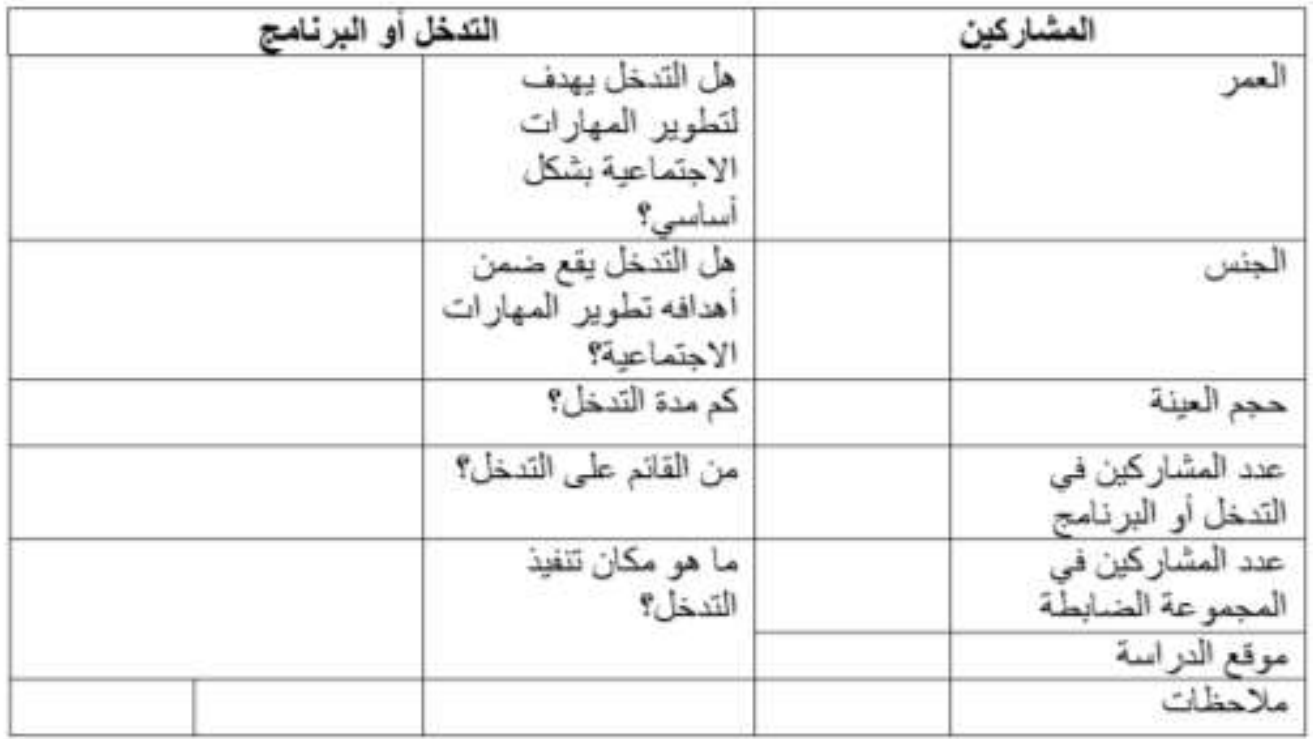

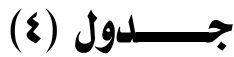

تابع نموذج لترميز بيانات الدراسة بالاعتماد على (PICOS)

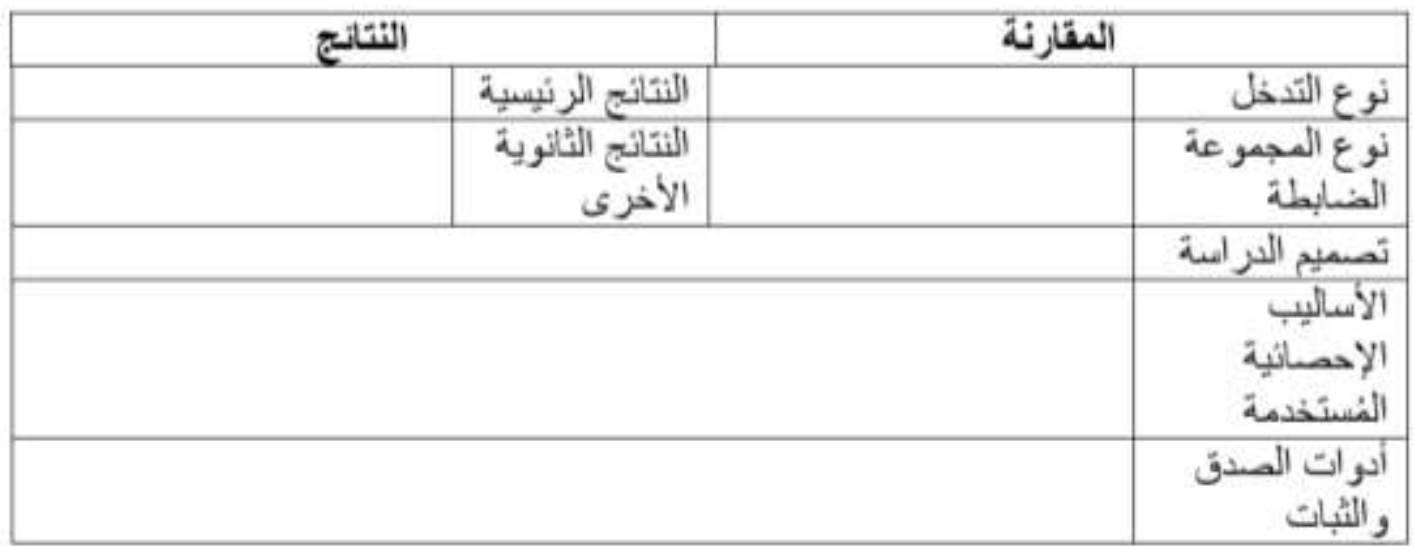




\section{جــــــ (0)}

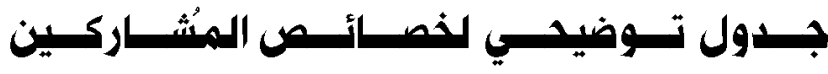

\begin{tabular}{|c|c|c|c|c|}
\hline المرحلة الدراسية & الجنس & العمر & العدد & 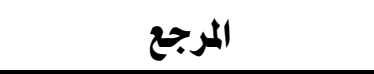 \\
\hline المرحلة الابتدائية & لم يُحدد & | لم يُحدد & $r$. & المعيقل (· ( • Y). \\
\hline المرحلة الابتدائية & • & 1 ا سنة & 17 & $\begin{array}{l}\text { Corkum et al. } \\
\text { (2010). }\end{array}$ \\
\hline رياض الأطفال & ذكور & كسنـــــــوات و آشــــــهور - & iv & $\begin{array}{l}\text { Reynolds et al. } \\
\text { (2014). }\end{array}$ \\
\hline المرحلة الابتدائية & لم يُحدد & 7-11 سنة & 0 & $\begin{array}{l}\text { Wilkes-Gillan et al. } \\
\text { (2014) }\end{array}$ \\
\hline رياض الأطفال & و 10\% منهم ذكور & ع سنوات & $\leq 0$ & Feil et al. (2016). \\
\hline | المرحلة الابتدائية & لم يُحدد & V- Y I سنة & rr & Pana et al. (2016). \\
\hline راليـــاض الأطفــــال & لم يُحدد & | & rq & $\begin{array}{l}\text { Wilkes-Gillan et al. } \\
\text { (2016) }\end{array}$ \\
\hline المرحلة الابتدائية & واحدة ذكـور وأنثــى & | | 1 سنة & 9 & $\begin{array}{lll}\text { Jijina } & \& & \text { Sinha } \\
(2016) & & \\
\end{array}$ \\
\hline المرحلة الابتدائية & ذكر & 1 1 سنوات & 1 & 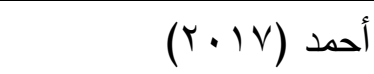 \\
\hline المرحلة الابتدائية & أناث ذكور وثـلاث & 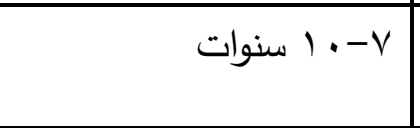 & rq & $\begin{array}{l}\text { Campeño-Martínez } \\
\text { et al. (2017) }\end{array}$ \\
\hline | المرحلة الابتدائية & لم يحدد & V- - ا سنوات & 17 & $\begin{array}{lll}\text { Jurjadeh et } & \text { al. } \\
(2018) & & \\
\end{array}$ \\
\hline المرحلة الابتدائية & \% ذكور \% & 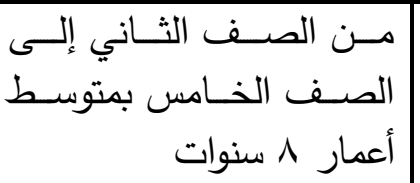 & 1ro & $\begin{array}{lll}\begin{array}{l}\text { Pfiffner } \\
(2018)\end{array} & \text { et } & \text { al. }\end{array}$ \\
\hline المرحلة الابتدائية & لم يحدد & || | سنة & $\wedge$ & 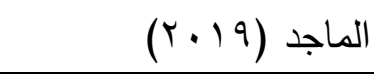 \\
\hline 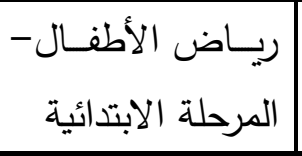 & r ذكور -r إناث & أشهر وشـر - 11 ســنة وتسـع & 7 & $\begin{array}{l}\text { Daffner et al. } \\
(2020)\end{array}$ \\
\hline
\end{tabular}




\section{جــــــ (7)}

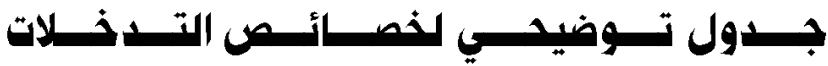

\begin{tabular}{|c|c|c|c|}
\hline النتيجة الرئيسية & التصميميم & ل ل ل & المرجع \\
\hline 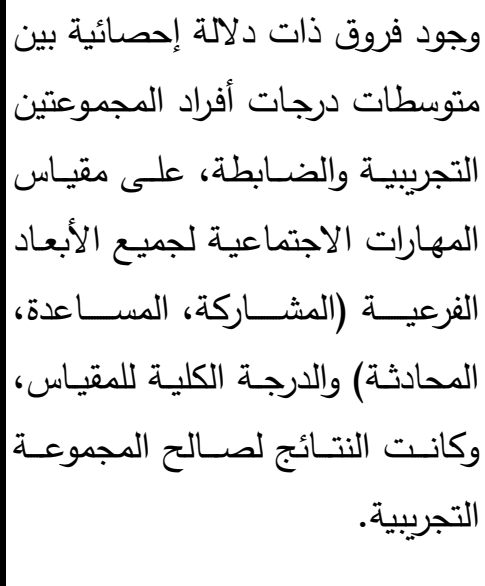 & 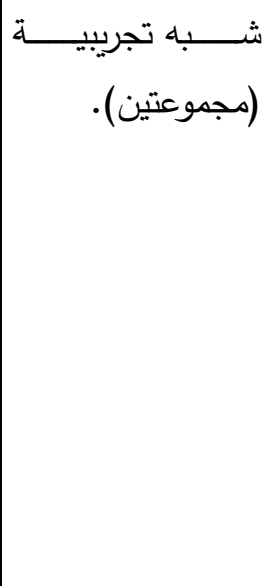 & 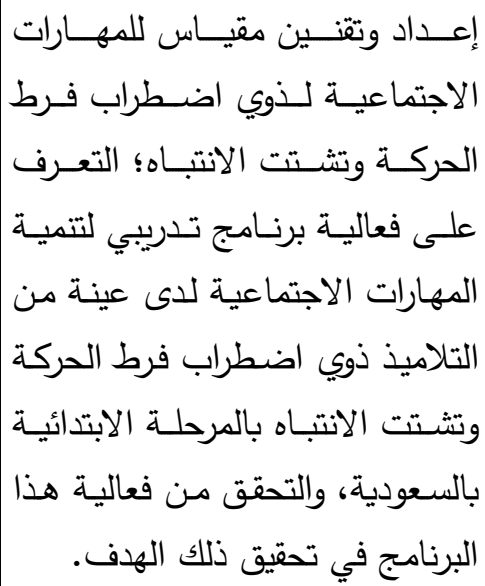 & 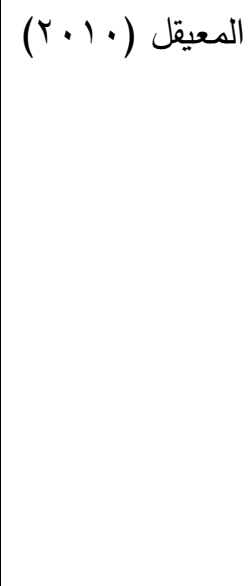 \\
\hline أثنار إلى أن هذا البرنامج كان فعالاً & 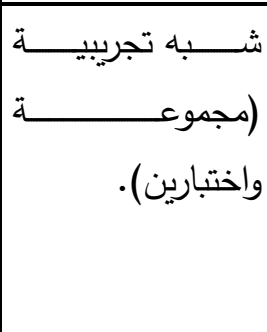 & 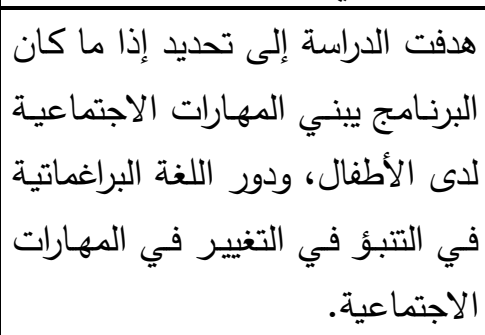 & $\begin{array}{l}\text { Corkum et al. } \\
(2010) .\end{array}$ \\
\hline تـأثير تـدخل الإدارة الذاتيـة في زيــادة & 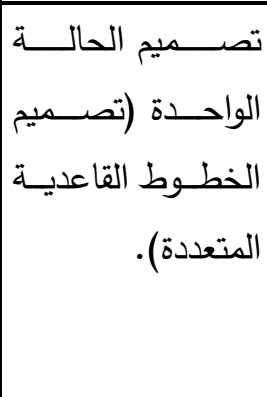 & 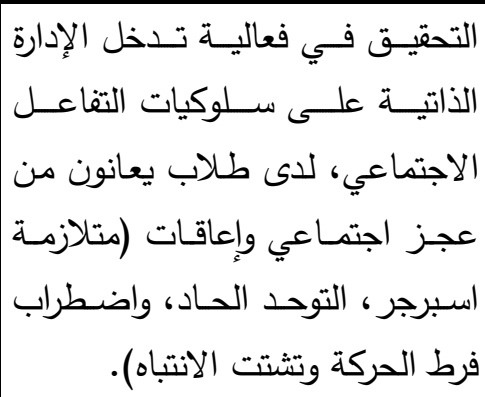 & $\begin{array}{l}\text { Reynolds et } \\
\text { al. }(2014) .\end{array}$ \\
\hline 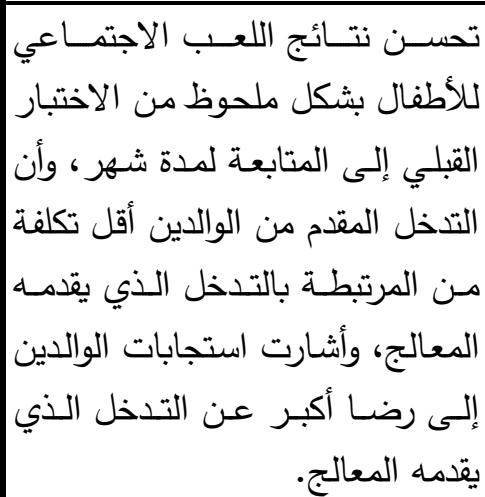 & 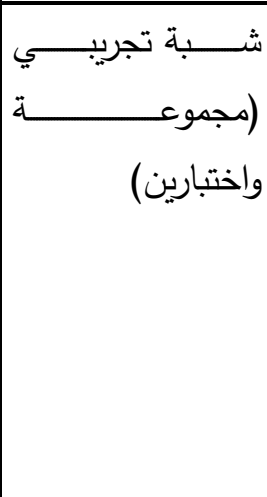 & 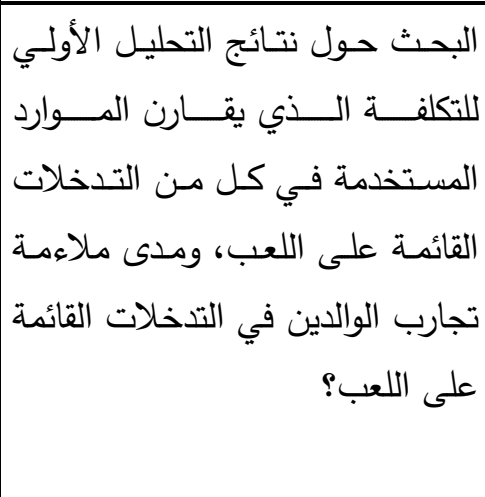 & $\begin{array}{l}\text { Wilkes- } \\
\text { Gillan et al. } \\
(2014)\end{array}$ \\
\hline
\end{tabular}




\section{أ / موضي الهويمل \& أ/ نوضاء القحطاني \& أ/ هناء الرويلي تطوير المهارات الاجتماعية للأطفال ذوي فرط الحركة وتشتت الانتباه}

\begin{tabular}{|c|c|c|c|}
\hline النتيجة الرئيسية & التصميم & الهلدف & المرجع \\
\hline 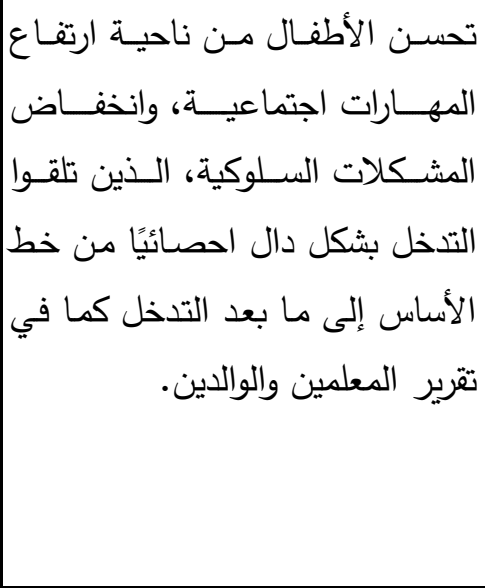 & 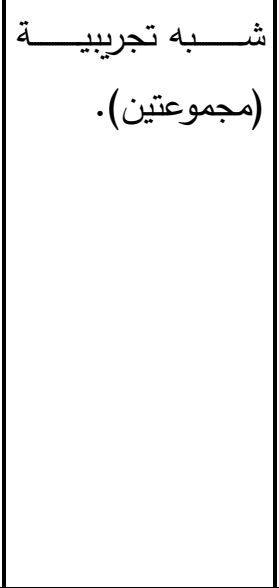 & 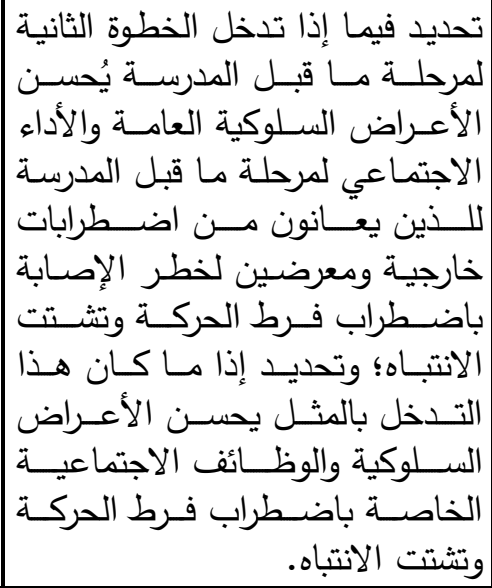 & $\begin{array}{l}\text { Feil et al. } \\
(2016) \text {. }\end{array}$ \\
\hline 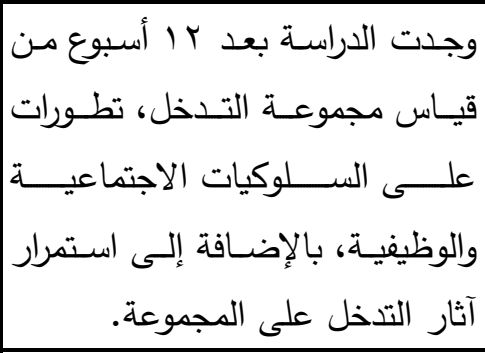 & 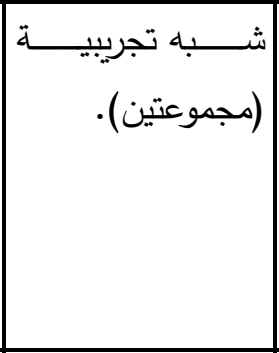 & 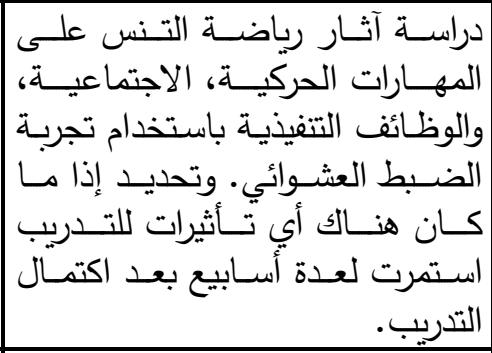 & $\begin{array}{l}\text { Pana et al. } \\
(2016) \text {. }\end{array}$ \\
\hline 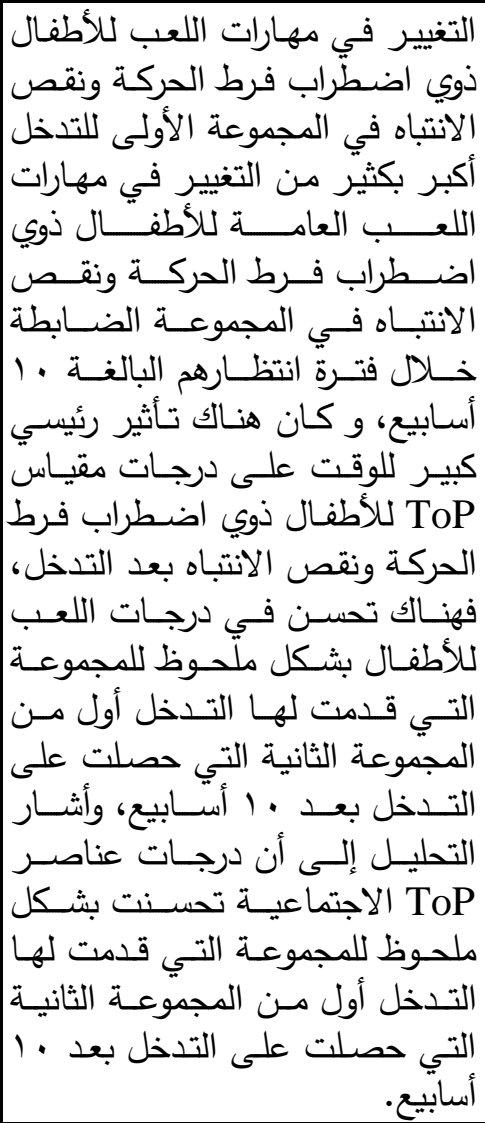 & شـريبية تمجوعتين) & 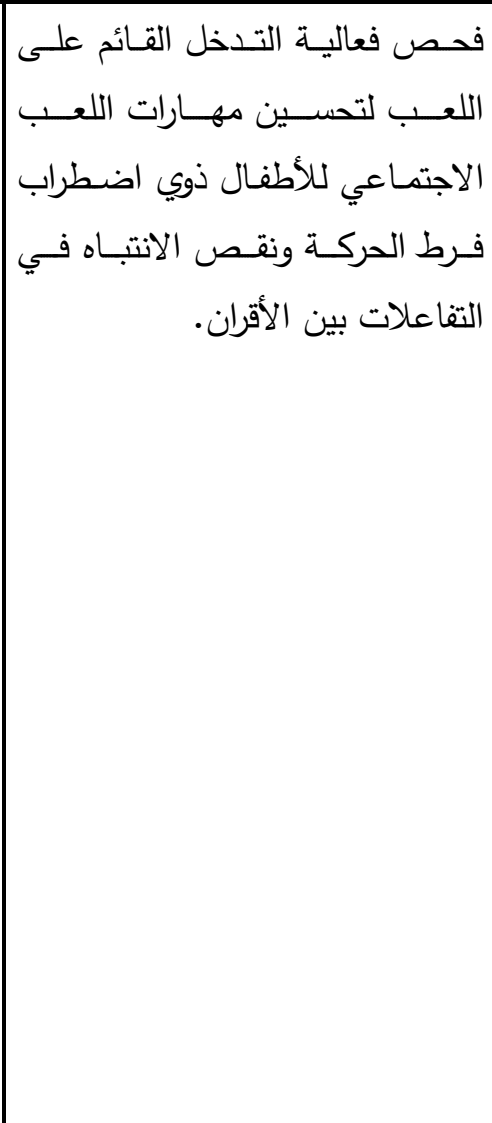 & $\begin{array}{l}\text { Wilkes- } \\
\text { Gillan et al. } \\
(2016)\end{array}$ \\
\hline
\end{tabular}




\begin{tabular}{|c|c|c|c|}
\hline النتيجة الرئيسية & التصميه & الهلف & المرجع \\
\hline 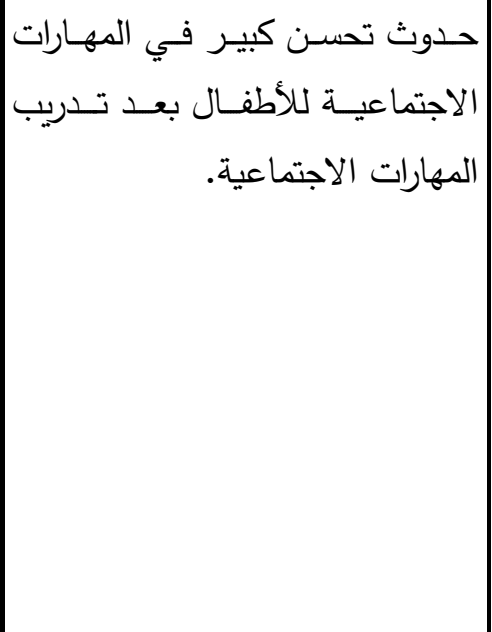 & 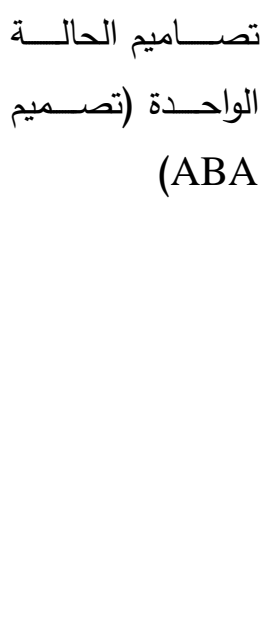 & 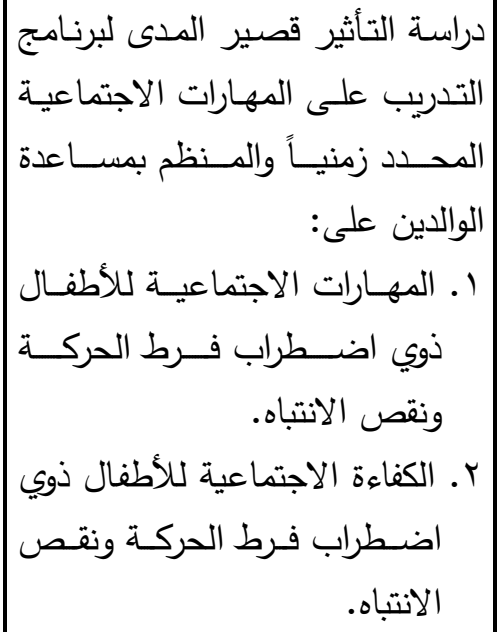 & $\mid \begin{array}{l}\text { Jijina \& } \\
\text { Sinha (2016) } \\
\\
\end{array}$ \\
\hline 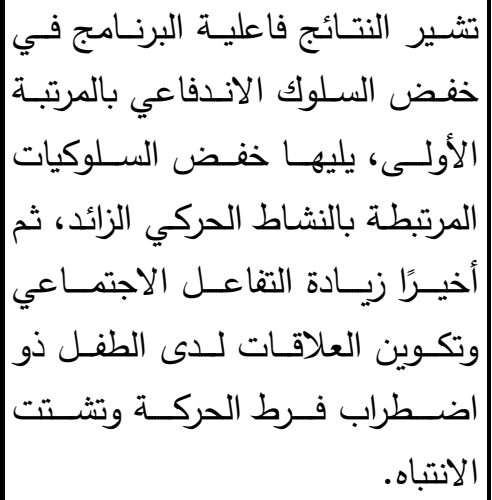 & تصـــــاميم الحالـــــة & 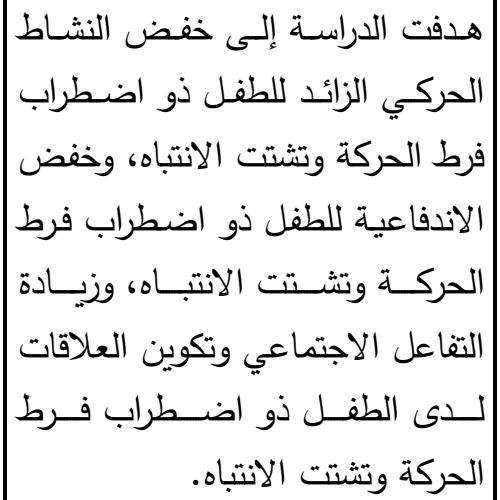 & 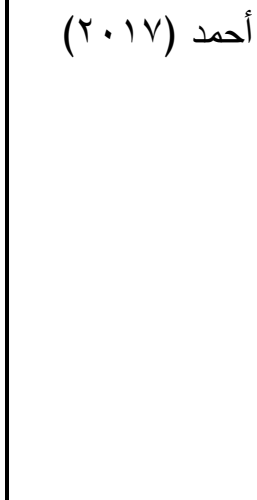 \\
\hline 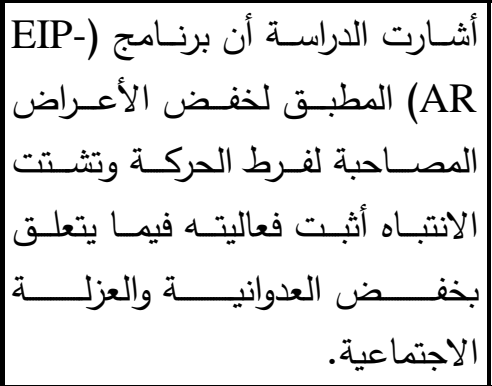 & 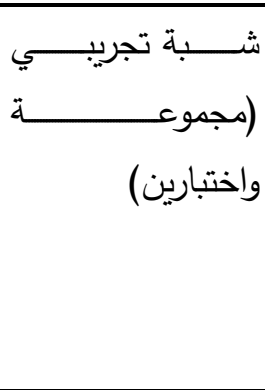 & 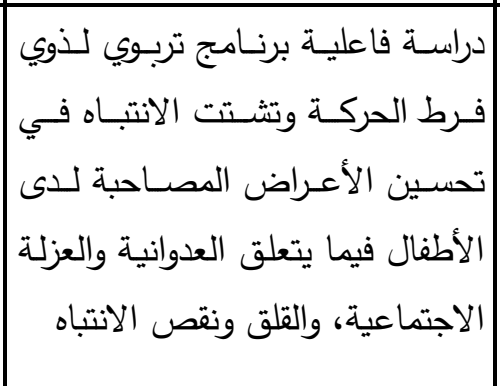 & \begin{tabular}{|l} 
Campeño- \\
Martínez \\
al. (2017) \\
\end{tabular} \\
\hline 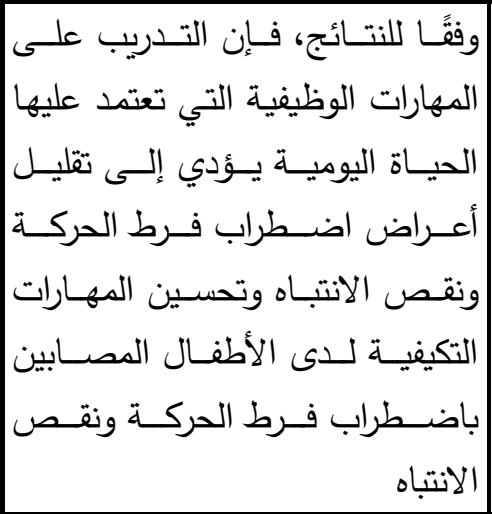 & 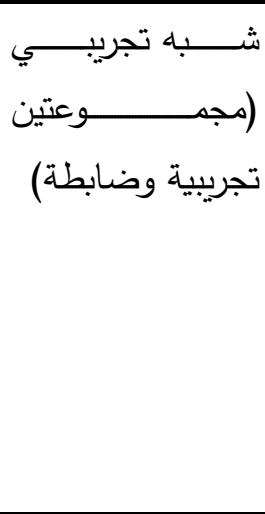 & 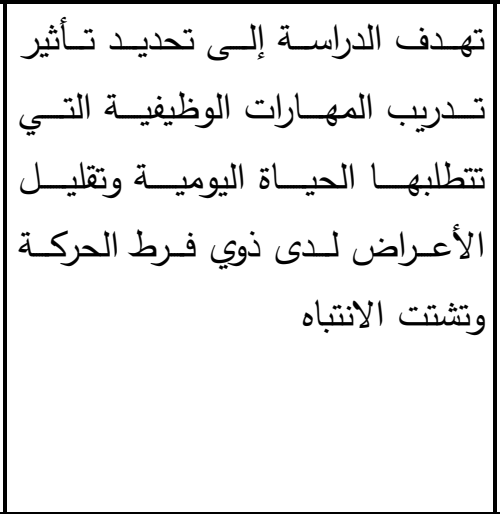 & \begin{tabular}{|l} 
Jurjadeh et \\
al. $(2018)$
\end{tabular} \\
\hline
\end{tabular}


أ / موضي الهويمل \& أ/ نوضاء القحطاني \& أ/ هناء الرويلي تطوير المثارات الاجتماعية للأطفال ذوي فرط الحركة وتشتت الانتباه

\begin{tabular}{|c|c|c|c|}
\hline النتيجة الرئيسية & التصميه & الهدف & المرجع \\
\hline 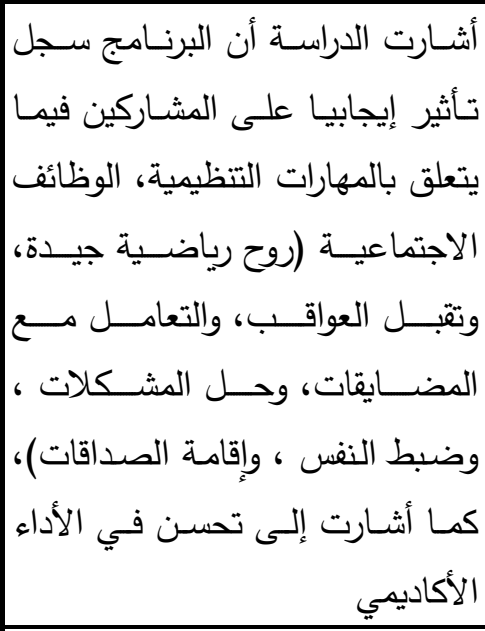 & 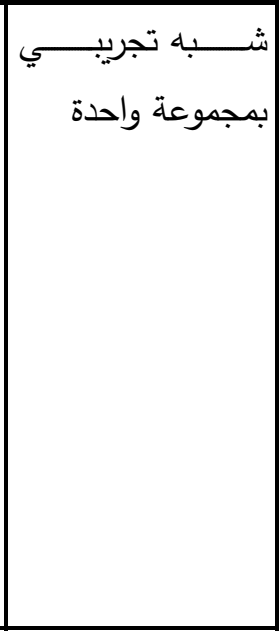 & 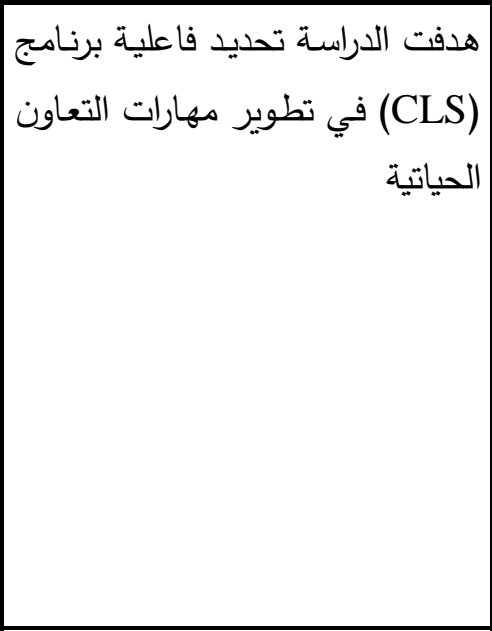 & $\begin{array}{l}\text { Pfiffner et al. } \\
(2018)\end{array}$ \\
\hline 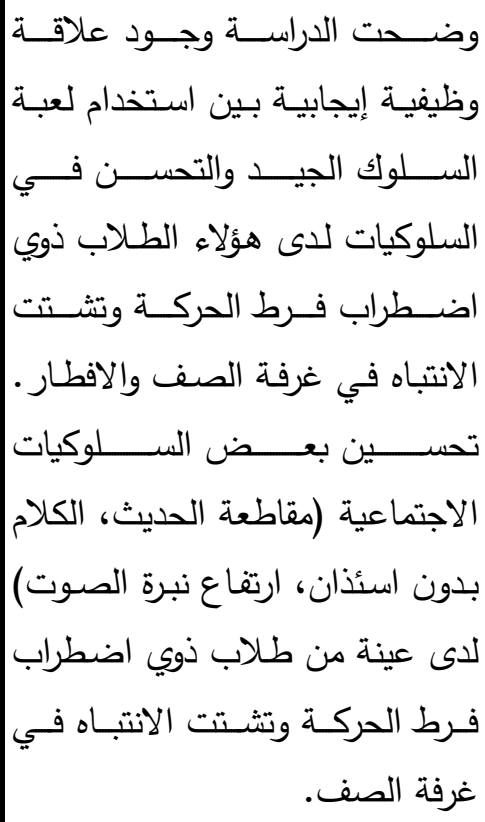 & 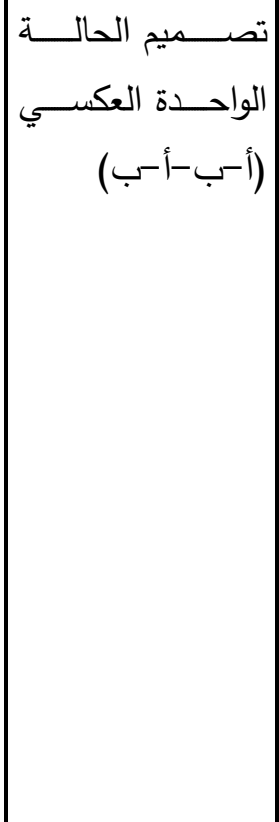 & 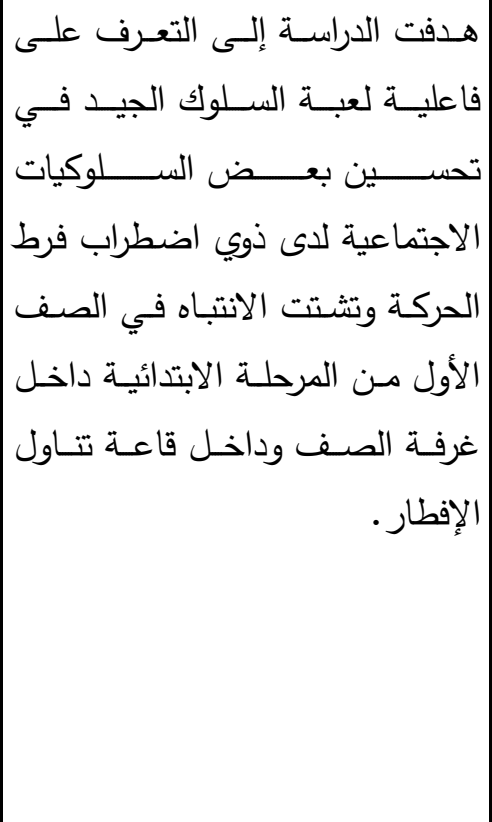 & الماجد (19 + r) \\
\hline 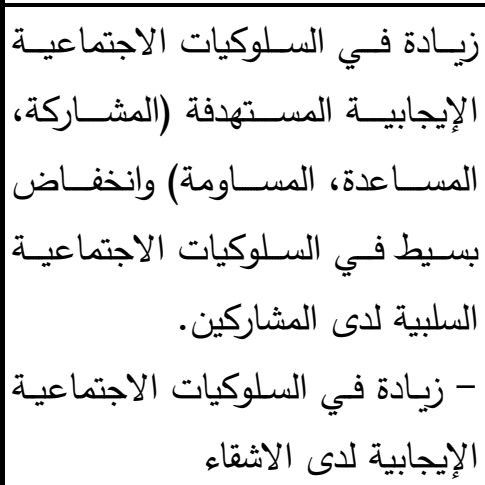 & التصــــاميم الحالــــة & 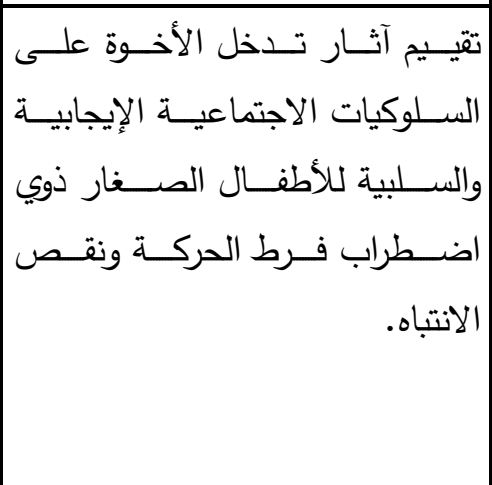 & $\begin{array}{l}\text { Daffner et al. } \\
(2020)\end{array}$ \\
\hline
\end{tabular}




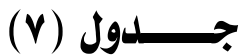

جدول توضيدي للأساليب الإحصائية ومصداقية الأدوات

\begin{tabular}{|c|c|c|}
\hline صلق وثبات الأدوات & الأساليب الإحصائية & المرجع \\
\hline 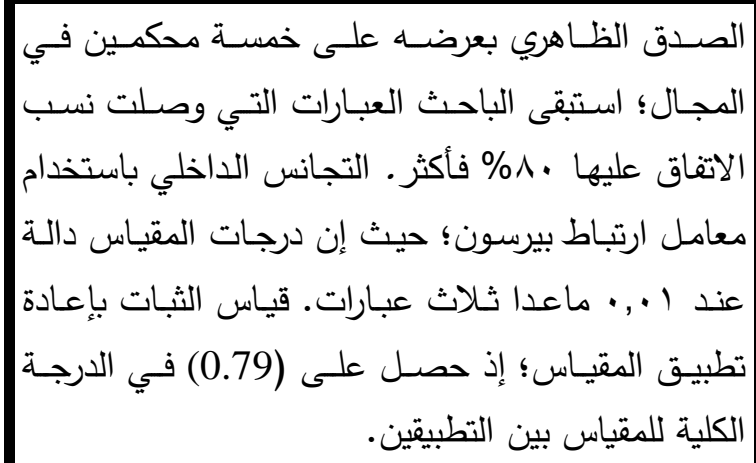 & | & 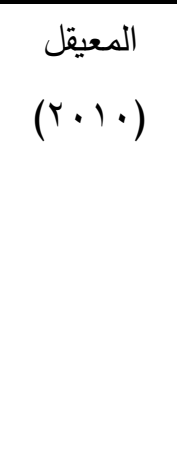 \\
\hline 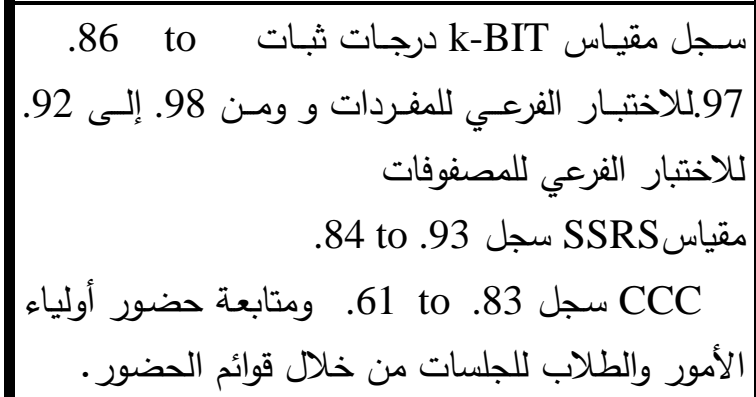 & | اختبـار ت- اختبـار ANOVA ، الانحدار الهرمي & $\begin{array}{l}\text { Corkum } \\
\text { et al. } \\
\cdot(r \cdot 1 \cdot)\end{array}$ \\
\hline 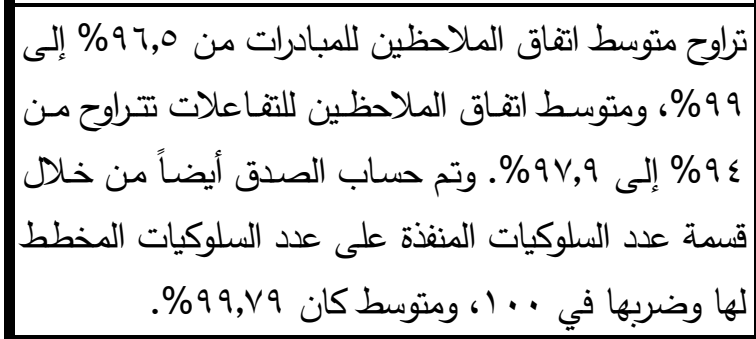 & 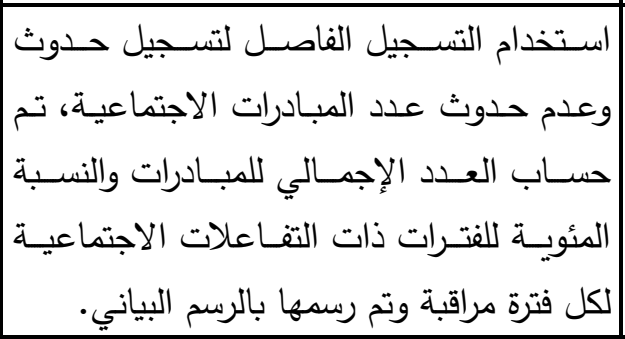 & $\begin{array}{l}\text { Reynolds } \\
\text { et al. } \\
\cdot(r \cdot l \varepsilon)\end{array}$ \\
\hline 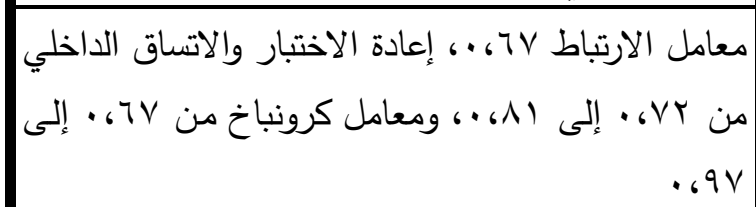 & 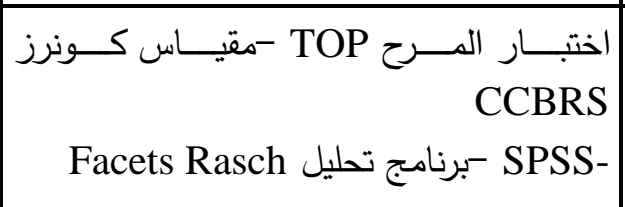 & $\begin{array}{l}\text { Wilkes- } \\
\text { Gillan et } \\
(r \cdot, \varepsilon) \text { al. }\end{array}$ \\
\hline 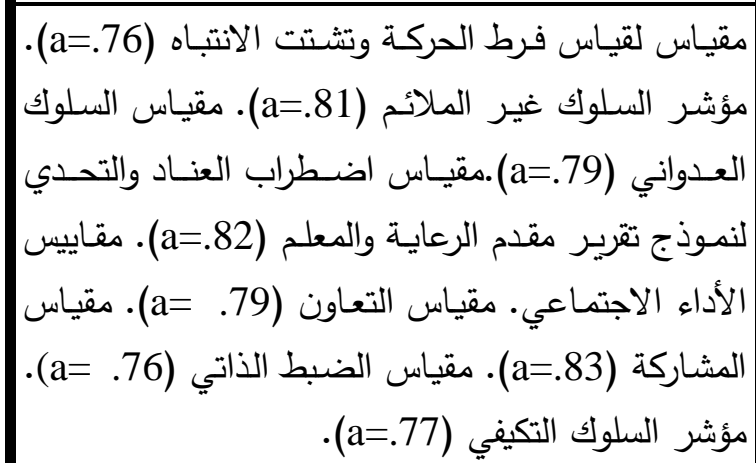 & 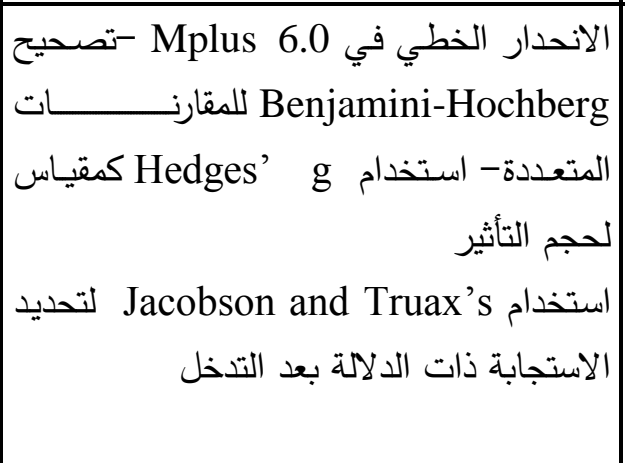 & $\begin{array}{l}\text { Feil et al. } \\
\cdot(r \cdot 1 \tau)\end{array}$ \\
\hline
\end{tabular}


أ / موضي الهويمل \& أ/ نوضاء القحطاني \& أ/ هناء الرويلي تطوير الممارات الاجتماعية للأطفال ذوي فرط الحركة وتشتت الانتباه

\begin{tabular}{|c|c|c|}
\hline صلق وثبات الأدوات & الأساليب الإحصائية & المرجع \\
\hline ثبات (r=0.85). & 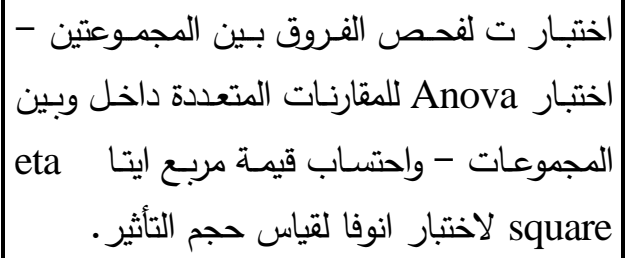 & $\begin{array}{l}\text { Pana et al. } \\
\cdot(r \cdot 1 \tau)\end{array}$ \\
\hline 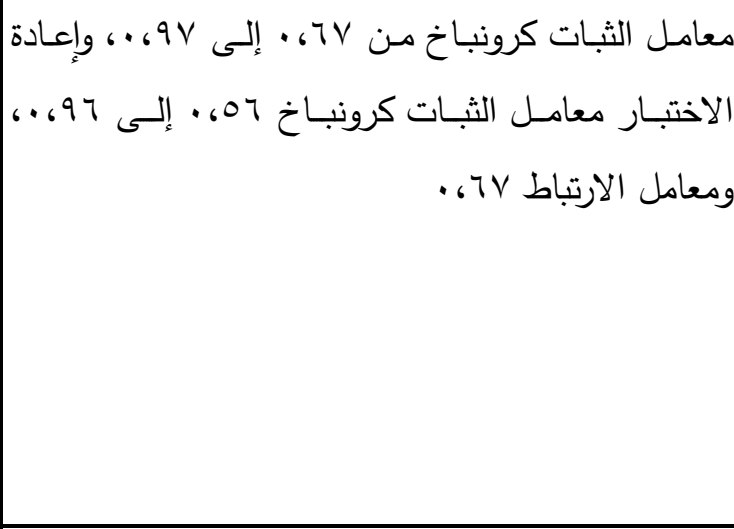 & 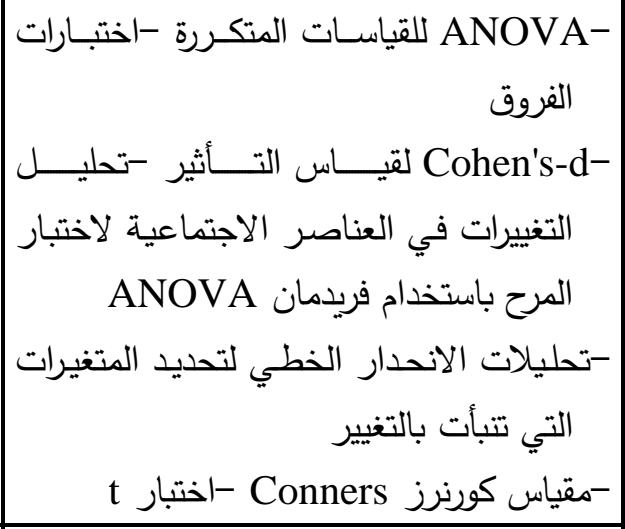 & $\begin{array}{l}\text { Wilkes- } \\
\text { Gillan et } \\
(r \cdot \mid \tau) \text { al. }\end{array}$ \\
\hline 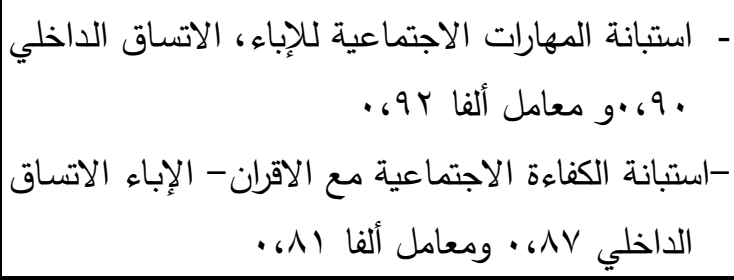 & 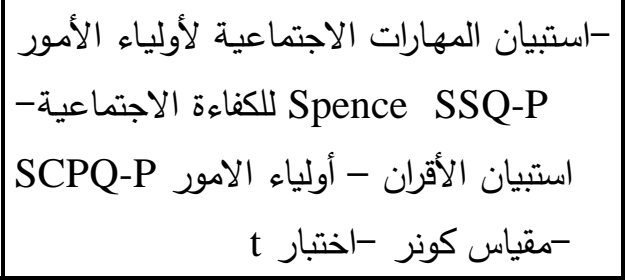 & $\begin{array}{l}\text { Jijina \& } \\
\text { Sinha } \\
(r \cdot 17)\end{array}$ \\
\hline 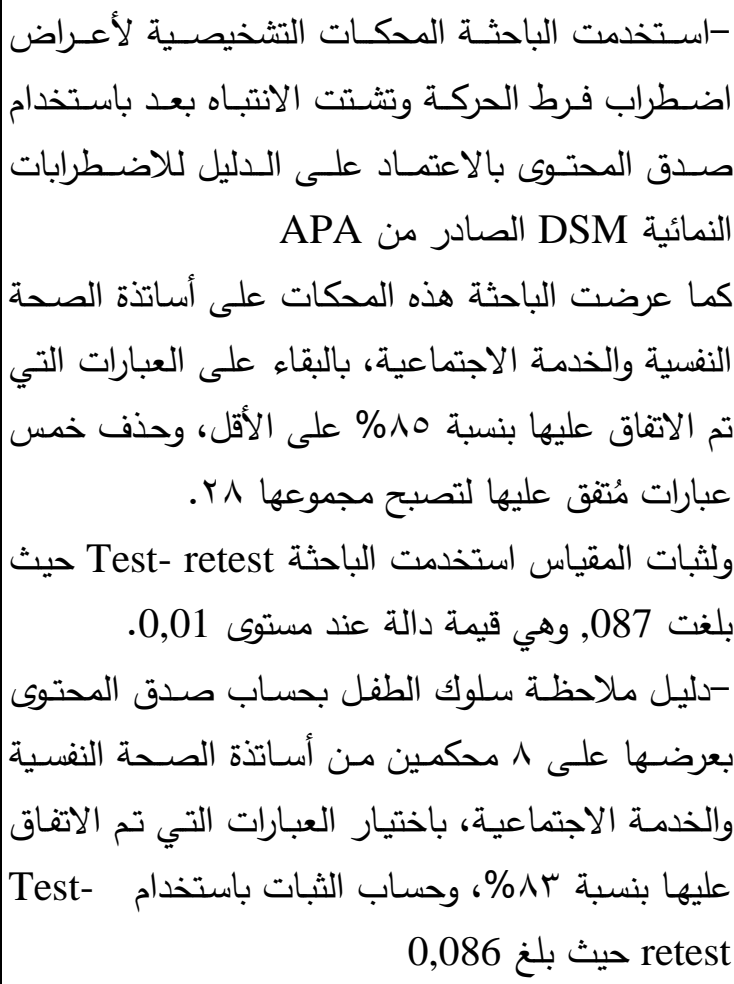 & 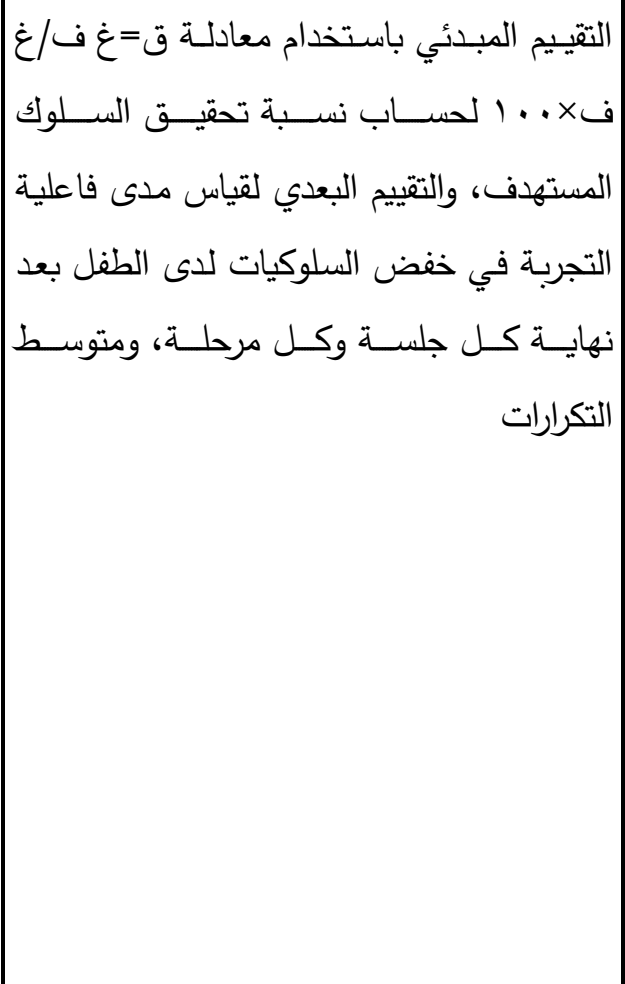 & $\begin{array}{c}\text { أحمد }(r \cdot I V) \\
(r \cdot 1 /)\end{array}$ \\
\hline
\end{tabular}




\begin{tabular}{|c|c|c|}
\hline & كائية & المر \\
\hline 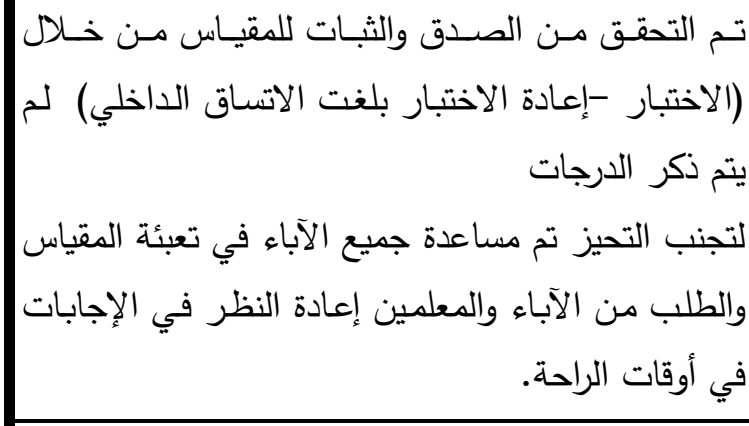 & 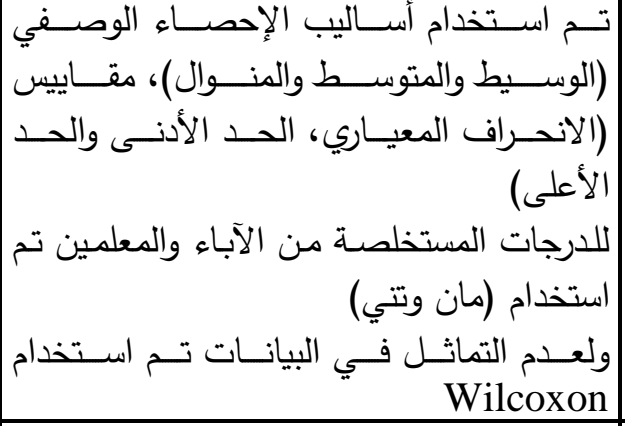 & $\begin{array}{l}\text { Campeño- } \\
\text { Martínez } \\
\text { et al. } \\
(r \cdot I v)\end{array}$ \\
\hline 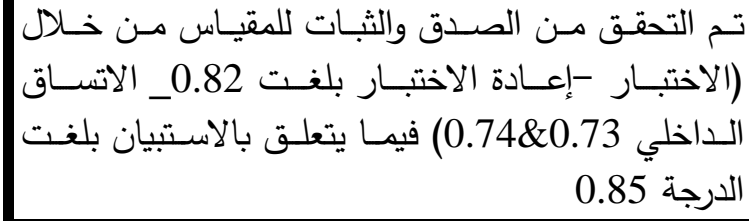 & 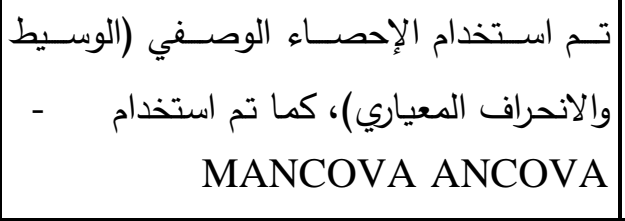 & $\begin{array}{l}\text { Jurjadeh } \\
\text { et al. } \\
(2018)\end{array}$ \\
\hline 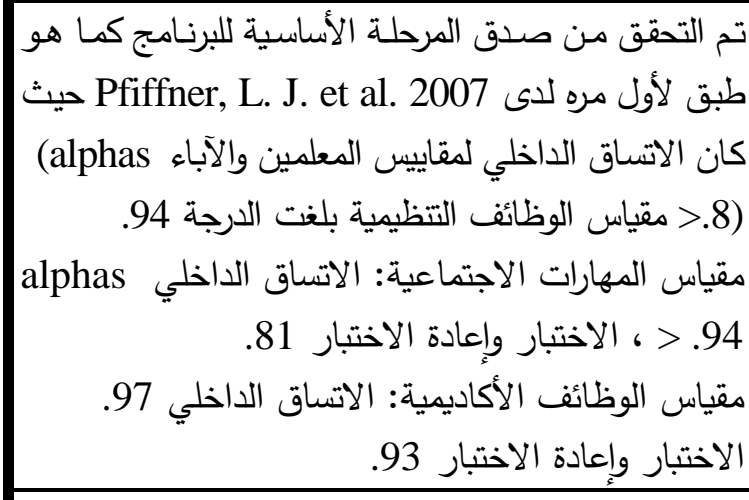 & 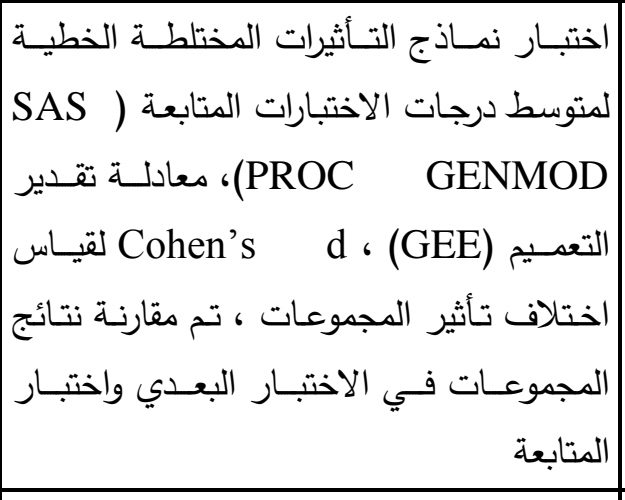 & $\begin{array}{l}\text { Pfiffner et } \\
\text { al. } \\
(2018)\end{array}$ \\
\hline نسبة اتفاق الملاحظين في الفصل بو\%\%، وغرفة الطع & |القصوى - القيمة الدنيا - الانحراف المعياري- القيمة & $\begin{array}{l}\text { الماجد } \\
(r \cdot 19)\end{array}$ \\
\hline 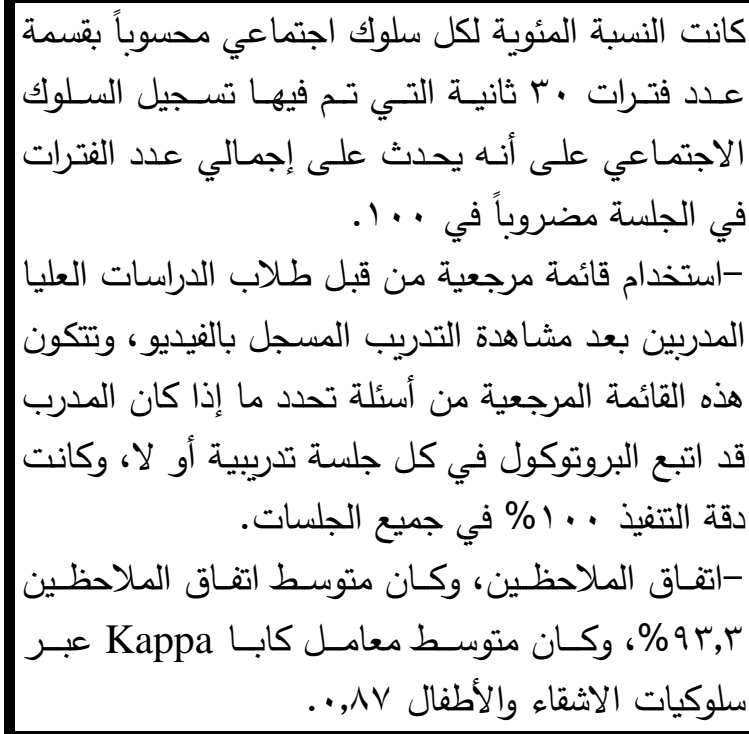 & 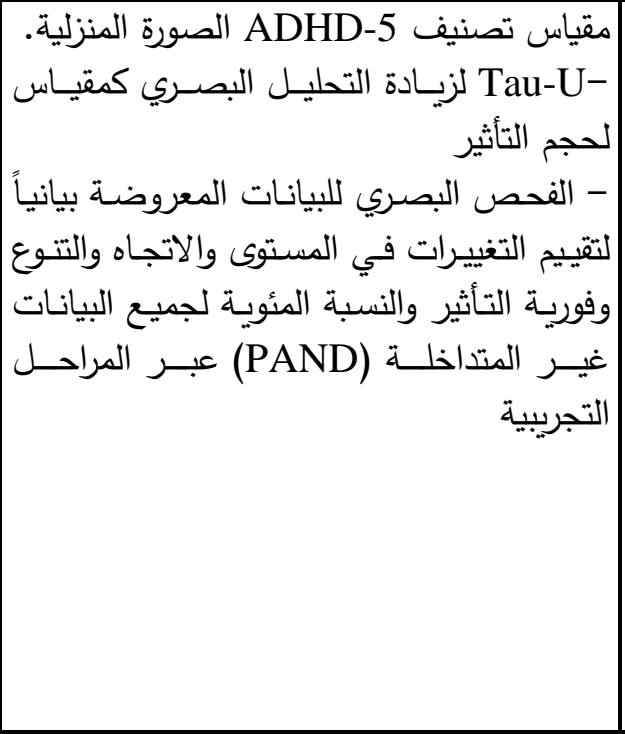 & $\begin{array}{l}\text { Daffner et } \\
\text { al. } \\
(2020)\end{array}$ \\
\hline
\end{tabular}

